\title{
Controlling the nuclearity and topology of cobalt complexes through hydration at the ppm level $\dagger$
}

Raúl Castañeda, (10) Mathieu Rouzières, ${ }^{\mathrm{b}}$ Rodolphe Clérac (D) $\star^{\mathrm{b}}$ and Jaclyn L. Brusso (10*a

Through ppm level control over the degree of hydration (e.g., 300 ppm vs. 10000 ppm), the nuclearity and topology of cobalt complexes can be tailored, as demonstrated here. This was achieved by employing $\mathrm{N}$-imidoylamidine ligands, which possess both bidentate and tridentate coordination sites, affording mono-, tri- and hexanuclear cobalt complexes. Structural characterization and magnetic analysis were used to elucidate the spin state of the cobalt ions, which reveal a unique combination of low and high spin states within the polynuclear systems. 
Complexes comprised of transition metal ions coordinated to bidentate organic ligands such as acetylacetonate (acac; Chart 1) and 1,3-diketoiminate (nacnac), or tridentate ligands like terpyridine (terpy) have been extensively studied for a number of applications including, but not limited to, the reduction of carbon dioxide to oxalate, ${ }^{1}$ water splitting, ${ }^{2}$ coupling reactions, ${ }^{3,4}$ magnetic materials ${ }^{5,6}$ and molecular switches. ${ }^{7}$ Although much less studied, $\mathrm{N}$-imidoylamidine (ImAm; Chart 1) ligands may be considered as triaza analogues of acac/nacnac, representing excellent candidates for the development of coordination complexes. Furthermore, resulting from the presence of the central nitrogen atom within the triaza moiety, sagacious selection of the $\beta$-substituents facilitates the development of two distinct coordination environments within a single rigid framework.

Interestingly, while $N$-imidoylamidine based ligands possessing both a bidentate and tridentate coordination site hold great appeal, only a few examples can be found in literature. ${ }^{8}$ This is likely due to the generation of these ligands, which until recently were only prepared in one pot synthetic procedures through metal-assisted transformations. For example, the first ImAm-based complex to be reported was prepared through thermal decomposition of triazine in the presence of copper(II), resulting in the formation of a square planar copper complex in which unsubstituted ImAm is coordinated in a bidentate fashion. ${ }^{9}$ Two years later, Boča et al. synthesized a similar system via nucleophilic addition of methanol to

${ }^{a}$ Department of Chemistry and Biomolecular Sciences, University of Ottawa, 150 Louis Pasteur, Ottawa, Ontario K1N 6N5, Canada. E-mail: jbrusso@uottawa.ca ${ }^{b}$ Univ. Bordeaux, CNRS, Centre de Recherche Paul Pascal, UMR 5031, 33600 Pessac, France. E-mail: clearc@crpp-bordeaux.cnrs.fr dicyanamidinate, resulting in a methoxy substituted ImAm ligand. ${ }^{10}$ These results inspired the synthesis of a trinuclear copper complex prepared under similar conditions with the addition of pyrazole. This reaction afforded $N$-1-pyrazolylimidoyl-1-pyrazolylamidine ( $\left.\mathbf{P z}_{2} \mathbf{I m A m}\right)$, in which two $\mathbf{P} \mathbf{z}_{2} \mathbf{I m A m}$ ligands coordinate in a bidentate fashion to a central $\mathrm{Cu}^{\text {II }}$ ion with two additional $\mathrm{Cu}^{\text {II }}$ metal ions bound to the tridentate pocket of each $\mathbf{P z}_{2} \mathbf{I m A m}{ }^{11}$ Subsequent work employing the aforementioned trinuclear moiety as the starting material and reacting it with EDTA enabled isolation of $\left[\mathrm{Cu}^{\mathrm{II}}\left(\mathrm{Pz}_{2} \mathrm{ImAm}\right)_{2}\right]$ and therefore facilitated the development of hetero-trinuclear complexes $\left[\mathrm{M}_{2} \mathrm{Cu}^{\mathrm{II}}\left(\mathrm{Pz}_{2} \mathrm{ImAm}\right)_{2}\right]\left[\mathrm{ClO}_{4}\right]_{4}$ (where $\mathrm{M}=$ $\mathrm{Mn}, \mathrm{Co}$ or Ni). ${ }^{12}$ In these systems, Pz $\mathbf{I m A m}$ acts as a ferromagnetic linker between metal ion sites. ${ }^{11,12}$ Recently, Starikova ${ }^{13}$ conducted a computational study to predict the magnetic properties of trinuclear heterometallic complexes of the general formula $\left[\mathrm{M}_{2}^{\mathrm{II}} \mathrm{M}^{\mathrm{II}}\left(\mathrm{Pz}_{2} \mathrm{ImAm}\right)_{2}\right.$ terpy $\left.{ }_{2}\right]$, in which the central $\mathrm{M}^{\mathrm{II}}$ ion coordinates to two $\mathbf{P z _ { 2 }}$ ImAm in either square planar or tetrahedral geometry. Using various first row transition metal ions $\left(\mathrm{M}^{\mathrm{II}}\right)$, many of these systems were predicted to exhibit two-step spin-crossover phenomenon. ${ }^{13}$

Similar ligand frameworks incorporating pyridyl (N-2pyridylimidoyl-2-pyridylamidine; $\left.\mathbf{P y}_{2} \mathbf{I m A m}\right)$ or pyrimidyl $(\mathrm{N}-2$ pyrimidylimidoyl-2-pyrimidylamidine; $\mathbf{P m}_{\mathbf{2}} \mathbf{I m A m}$ ) moieties at
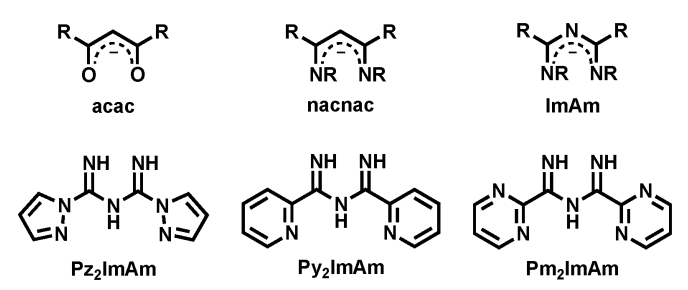

Chart 1 Structure of acetylacetonate (acac), 1,3-diketoiminate (nacnac) and $N$-imidoylamidine (ImAm) ligands including $\mathbf{P z}_{\mathbf{2}} \mathbf{I m A m}, \mathbf{P y}_{\mathbf{2}} \mathbf{I m A m}$ and $\mathrm{Pm}_{2}$ ImAm. 
the $\beta$-position have also been reported; ${ }^{4,14-17}$ however, here again the ImAm ligands were prepared through metal-assisted transformations using a metal salt and a pyridyl/pyrimidyl synthon. For example, a copper coordination polymer or dimer can be isolated following decomposition of either tris(2pyridyl)triazine ${ }^{14}$ or tris(2-pyrimidyl)triazine, ${ }^{15}$ respectively, in the presence of copper(II) salts. Similar to the $\mathbf{P} \mathbf{z}_{2}$ ImAm complexes, the ligand acts to ferromagnetically couple the adjoining $\mathrm{Cu}^{\mathrm{II}}$ ions. Py $\mathbf{P y}_{2} \mathbf{I m A m}$ complexes have also been reported through in situ reactions of 2-cyanidopyridine and butan-2-one oxime with $\mathrm{PdCl}_{2}$ to make a palladium(II) square planar complex, ${ }^{4}$ or pyridine-2-amidoxime with $\mathrm{MnF}_{2}$ resulting in a manganese(III) octahedral complex. ${ }^{17}$

While these studies demonstrate the potential of ImAm ligands, a significant drawback lies in their synthesis, which relies on relatively low yielding in situ reactions. ${ }^{8}$ Recently, our group developed the synthesis of both $\mathbf{P y}_{2} \mathbf{I m A m}{ }^{18}$ and $\mathbf{P m}_{2} \operatorname{ImAm}^{19}$ in large scale without metal ion assistance, thereby enabling us to tailor the reaction conditions in order to selectively bind to the bidentate and/or tridentate coordination sites. In that regard, we have established the synthetic methodology to control the topology with first row transition metal ions (e.g., $\mathrm{Mn}, \mathrm{Fe}, \mathrm{Co}$ ) affording mononuclear, dinuclear and tetranuclear complexes. ${ }^{20,21}$ These studies demonstrate that the key factor in controlling coordination site preference (i.e., bidentate $v s$. tridentate) is the presence (or absence) of a weak acid. Having resolved the necessary conditions to selectively coordinate to specific sites in ImAm-based ligands, and determined the methodology to isolate tetranuclear $\left[\mathrm{M}_{4}\left(\mathrm{Pm}_{2} \mathrm{ImAm}\right)_{3} \mathrm{Cl}_{x}\right]$ complexes (where $x=6$ or 9 ), the versatility of this ligand framework was probed in the development of polynuclear complexes possessing square planar geometry at the central metal ion. To that end, presented herein are the synthesis, structural analysis and magnetic characterization of the trinuclear and hexanuclear complexes, $\left[\mathrm{Co}_{3}{ }_{3}\left(\mathrm{Pm}_{2} \operatorname{ImAm}\right)_{2} \mathrm{Cl}_{4}\right]$ and $\left[\mathrm{Co}_{6}{ }_{6}(\mu-\mathrm{Cl})_{2}\left(\mathrm{Pm}_{2} \operatorname{ImAm}\right)_{4} \mathrm{Cl}_{8}\right]$, respectively. To help elucidate the electronic structure of the polynuclear complexes, the structural and magnetic properties of the mononuclear species, [ $\left.\mathbf{C o}^{\mathbf{I I}}\left(\mathbf{P} \mathbf{y}_{2} \mathbf{I m A m}\right)_{2}\right]$, is also reported. These results reveal a unique combination of spin states within the polynuclear complexes, namely low-spin (LS) $\mathrm{Co}^{\text {II }}$ central ions and high-spin (HS) $\mathrm{Co}^{\mathrm{II}}$ ions at the periphery, where the nuclearity and topology are determined by precise control at the ppm level (e.g., $300 \mathrm{ppm} v s .10000 \mathrm{ppm}$ ) of hydration.

As reported, the coordination environment of first row transition metals in either a bidentate or tridentate fashion with ImAm ligands can be controlled by tailoring the reaction conditions. ${ }^{20}$ Following a similar procedure, selective bidentate coordination was achieved by employing basic reaction media. The key difference here is the use of inert conditions, which led to the isolation of $\left[\mathbf{C o}^{\mathbf{I I}}\left(\mathbf{P y}_{2} \mathbf{I m A m}\right)_{2}\right]$, as opposed to its octahedrally coordinated analog $\left[\mathbf{C o}^{\text {III }}\left(\mathbf{P y}_{2} \mathbf{I m A m}\right)_{3}\right] \cdot{ }^{20}$ More specifically, [Co' $\left.\mathbf{\text { II }}\left(\mathbf{P y}_{2} \mathbf{I m A m}\right)_{2}\right]$ can be prepared on a multigram scale by combining a solution of $\mathbf{P y}_{2} \mathbf{I m A m}$ and triethylamine $\left(\mathrm{Et}_{3} \mathrm{~N}\right)$ in acetonitrile $\left(\mathrm{CH}_{3} \mathrm{CN}\right)$ with a dimethylformamide (DMF) solution of $\mathrm{Co}(\mathrm{acac})_{2}$ under inert atmosphere (Scheme 1). After leaving the resulting solution to stand for three days, orange

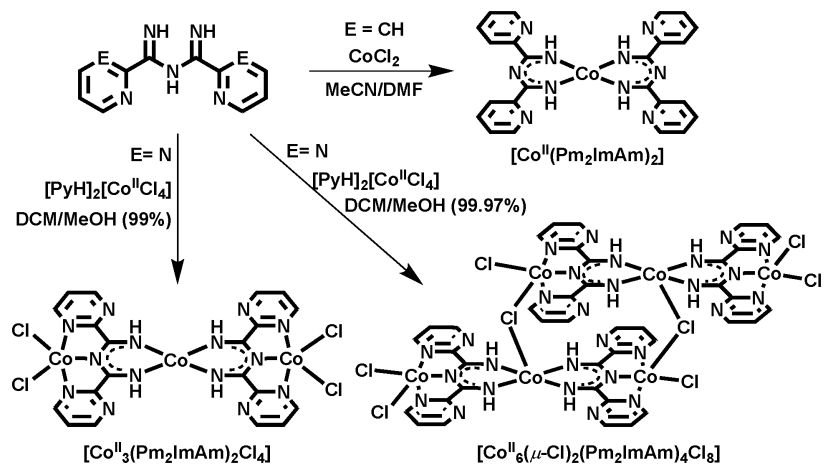

Scheme 1 Synthesis of [Co" $\left.\left(\mathrm{Py}_{2} \mathrm{ImAm}\right)_{2}\right],\left[\mathrm{Co}_{3}{ }_{3}\left(\mathrm{Pm}_{2} \mathrm{ImAm}\right)_{2} \mathrm{Cl}_{4}\right] \cdot 5 \mathrm{H}_{2} \mathrm{O}$ and $\left[\mathrm{Co}_{6}{ }_{6}(\mu-\mathrm{Cl})_{2}\left(\mathrm{Pm}_{2} \mathrm{ImAm}\right)_{4} \mathrm{Cl}_{8}\right] \cdot 2 \mathrm{CH}_{3} \mathrm{OH} \cdot 2 \mathrm{CH}_{2} \mathrm{Cl}_{2}$ employing Py 2 ImAm and $\mathrm{Pm}_{2} \mathrm{ImAm}$ ligands.

block-like crystals suitable for X-ray analysis were obtained confirming the identity of $\left[\mathbf{C o}^{\mathbf{I I}}\left(\mathbf{P y}_{2} \mathbf{I m A m}\right)_{2}\right]$. In this complex, which crystallizes in the monoclinic space group $P 2_{1} / n$, the cobalt ion is coordinated to two $\mathbf{P y}_{2} \mathbf{I m A m}$ ligands in a bidentate fashion leading to a nearly ideal square planar configuration (Fig. 1a, Tables S1 and S2, ESI $\dagger$ ), a geometry and ligand field strength commonly associated with a low spin configuration. ${ }^{22,23}$ Deprotonation of the $N$-imidoylamidine ligands in $\left[\mathbf{C o}^{\mathrm{II}}\left(\mathbf{P y}_{2} \mathbf{I m A m}\right)_{2}\right]$ suggest an oxidation state of +2 for the cobalt ion, which is further supported by the magnetic analysis (vide infra). Within the supramolecular structure, the molecules arrange into a herringbone fashion (Fig. S4, ESI $\dagger$ ) leading to two $\pi-\pi$ interactions (3.6389(3) and 3.7593(3) ̊̊) between the pyridyl rings of the ligand framework on neighbouring complexes and a Co-Co distance of 7.738(1) Å.

Having isolated the mononuclear square planar cobalt complex, the next step was naturally to explore the possibility to synthesize polynuclear systems taking advantage of both coordination sites available within these $N$-imidoylamidine ligand frameworks. Previously, we demonstrated that the employment of metal salts containing slightly acidic counterions such as pyridinium was an effective method in the isolation of tetranuclear complexes with $\mathrm{N}$-imidoylamidines. ${ }^{21}$ In the same vein, both $\left[\mathrm{Co}_{3}{ }_{3}\left(\mathrm{Pm}_{2} \mathrm{ImAm}\right)_{2} \mathrm{Cl}_{4}\right]$ and $\left[\mathrm{Co}_{6}^{\mathrm{II}}(\boldsymbol{\mu}-\mathbf{C l})_{2}\left(\mathrm{Pm}_{2} \mathrm{ImAm}\right)_{4} \mathrm{Cl}_{8}\right]$ can be prepared upon adding a methanolic solution of bis(pyridinium)tetrachlorocobaltate(II) $\left([\mathrm{PyH}]_{2}\left[\mathbf{C o}^{\mathrm{II}} \mathbf{C l}_{4}\right]\right)$ to a stirring solution of

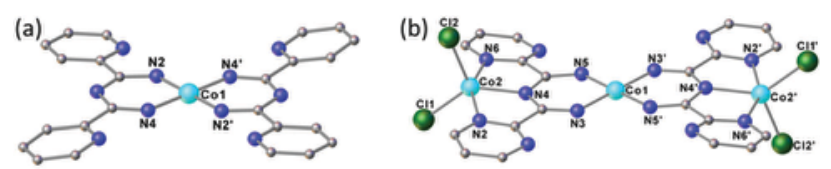

(c)

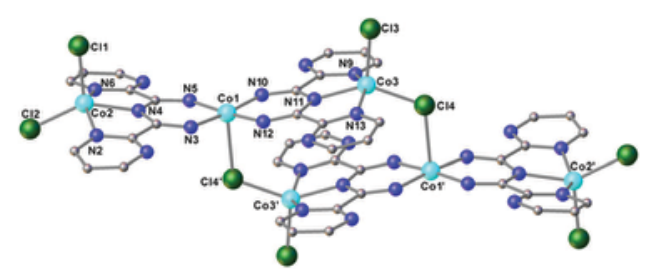

Fig. 1 Structural diagram of (a) $\left[\mathrm{Co}^{\prime \prime}\left(\mathrm{Py}_{2} \mathrm{ImAm}\right) \mathrm{Cl}_{2}\right]$, (b) $\left[\mathrm{Co}_{3}{ }_{3}\left(\mathrm{Pm}_{2} \mathrm{ImAm}\right)_{2} \mathrm{Cl}_{4}\right]$ and (c) $\left[\mathrm{Co}_{6}{ }_{6}\left(\mu-\mathrm{Cl}_{2}\left(\mathrm{Pm}_{2} \mathrm{ImAm}\right)_{4} \mathrm{Cl}_{8}\right]\right.$, with symmetry related positions labeled using the prime symbol. Hydrogen atoms have been removed for clarity. 
$\mathbf{P m} \mathbf{m}_{2} \mathbf{I m A m}$ in dichloromethane $\left(\mathrm{CH}_{2} \mathrm{Cl}_{2}\right)$ under inert conditions. The key difference between isolation of the trinuclear $v s$. hexanuclear cobalt complexes is in the degree of hydration of the methanol. In other words, the water content of the methanol leads to crystallization of complexes with different nuclearity. For example, when the water content is $10000 \mathrm{ppm}\left(99 \% \mathrm{CH}_{3} \mathrm{OH}\right)$ the trinuclear complex is formed, whereas the hexanuclear complex is isolated when $99.97 \%$ (300 ppm) $\mathrm{CH}_{3} \mathrm{OH}$ is employed. Interestingly, when the water content in the solvent is greater than $10000 \mathrm{ppm}$, nothing is recovered from the reaction mixture - i.e., neither complex is isolated nor any other coordination complex under these conditions. In either case, leaving the reaction mixture to stand for two days affords red plate-like crystals of $\left[\mathrm{Co}_{3}{ }_{3}\left(\mathbf{P m}_{2} \mathbf{I m A m}\right)_{2} \mathbf{C l}_{4}\right]$ $5 \mathbf{H}_{2} \mathrm{O}$ or block-like crystals of $\left[\mathrm{Co}_{6}{ }_{6}(\boldsymbol{\mu}-\mathbf{C l})_{2}\left(\mathrm{Pm}_{2} \mathrm{ImAm}\right)_{4} \mathbf{C l}_{8}\right]$ $2 \mathrm{CH}_{3} \mathbf{O H} \cdot 2 \mathrm{CH}_{2} \mathbf{C l}_{2}$ suitable for single crystal X-ray diffraction (SCXRD). For the reported compounds, bulk purity and composition of the as-synthesized products were confirmed through SCXRD and powder X-ray diffraction (PXRD; Fig. S1-S3, ESI $\dagger$ ). Interestingly, increasing the water content further by using benchtop $\mathrm{CH}_{3} \mathrm{OH}$ for example, did not lead to the production of any crystalline solids.

Crystals of $\left[\mathrm{Co}^{\mathrm{II}}{ }_{3}\left(\mathbf{P m}_{2} \mathrm{ImAm}\right)_{2} \mathbf{C l}_{\mathbf{4}}\right] \cdot \mathbf{5 H}_{\mathbf{2}} \mathrm{O}$, which belong to the triclinic $P \overline{1}$ space group, contain two crystallographically independent molecules in the asymmetric unit with a point of inversion located at the central cobalt ion of each molecule. Nonetheless, these crystallographically independent complexes have essentially the same geometry and metal to ligand bond distances (Table S5, ESI $\dagger$ ). In $\left[\mathbf{C o}_{3}{ }_{3}\left(\mathbf{P m}_{2} \mathbf{I m A m}\right)_{2} \mathbf{C l}_{4}\right] \cdot \mathbf{5 H}_{2} \mathbf{O}$, each $\mathbf{P m}_{\mathbf{2}} \mathbf{I m A m}$ ligand is anionic and coordinates to two Co ions resulting in two distinct Co moieties - one coordinated in a bidentate fashion, the other in the tridentate pocket of the ligand (Fig. 1b). The central Co ion, which is bound to two anionic $\mathbf{P m}_{2} \mathbf{I m A m}$ ligands in a bidentate fashion, adopts a nearly square planar environment that is very similar to that of the mononuclear complex $\left[\mathbf{C o} \mathbf{O}^{\mathrm{II}}\left(\mathbf{P y}_{2} \mathbf{I m A m}\right)_{2}\right]$ (as highlighted in the overlay of the two structures in Fig. S5, ESI $\dagger$ ). Comparing the Co-N distances of the central metal in $\left[\mathrm{Co}_{3}{ }_{3}\left(\mathbf{P m}_{2} \mathbf{I m A m}\right)_{2} \mathbf{C l}_{4}\right]$ to those of $\left[\mathbf{C o}^{\mathbf{I I}}\left(\mathbf{P y}_{2} \mathbf{I m A m}\right)_{2}\right]$ reveal a nominal elongation of these bonds upon development of the polynuclear complex (1.847(1)1.856(1) $\AA$ in [Co $\left.{ }^{\mathrm{II}}\left(\mathbf{P y}_{2} \mathbf{I m A m}\right)_{2}\right]$ to $1.86509(13)-1.88734(11) \AA$ in $\left.\left.\left[\mathrm{Co}_{3}{ }_{3} \mathbf{( P m} \mathbf{P m}_{2} \mathbf{I m A m}\right)_{2} \mathbf{C l}_{4}\right]\right)$. This slight elongation suggests the metal ion remains in the same oxidation (i.e., +2 ) and spin (vide infra) states for both complexes, and the Co-N distances of both complexes are in the expected range for low spin Co(II) ions. ${ }^{23-25}$ The outer cobalt ions ( $\mathrm{Co} 2$ and $\mathrm{Co} 4$ ) are pentacoordinate with the metal ion residing within the plane of the tridentate $\mathbf{P m}_{\mathbf{2}} \mathbf{I m A m}$ ligand. The remaining metal coordination environment is filled by two $\mathrm{Cl}$ anions above and below the plane of the ligand framework. Analysis of the coordination geometry using SHAPE $^{26}$ suggests the coordination environment about the peripheryl Co ions is in between square pyramidal and trigonal bipyramidal (Table S11 and Fig. S10, ESI $\dagger$ ). Interestingly, the coordination environment of the outer cobalt ions is very similar to that observed in the previously reported tridentate mononuclear complex $\left[\mathbf{C o}^{\mathbf{I I}}\left(\mathbf{P y}_{2} \mathbf{I m A m}\right) \mathbf{C l}_{2}\right]$ (Fig. S5, ESI $\left.\dagger\right) .{ }^{20}$ Based on the above mentioned similarities, along with charge balance, this would suggest an oxidation state of +2 for these cobalt ions. A review of related cobalt(II) complexes in literature that possess similar geometries and coordination spheres as $\mathrm{Co} 2$ and $\mathrm{Co} 4$ (i.e., one terpy-like ligand and two chloride ions) suggest these metal centres adopt high spin $S=3 / 2$ configurations based on structural arguments. ${ }^{6,27,28}$

Crystal packing of $\left[\mathrm{Co}_{3}{ }_{3}\left(\mathbf{P m}_{2} \mathrm{ImAm}\right)_{2} \mathbf{C l}_{4}\right] \cdot \mathbf{5 H}_{2} \mathrm{O}$ is comprised of columnar stacks of alternating complexes that are twisted by $85^{\circ}$ with respect to the neighbouring molecules above and below (Fig. S6, ESI $\dagger$ ). This structural feature likely results from the peripheral cobalt dichloride moiety, which is bulky enough to align the square planar portion of the complexes in a staggered fashion to one other (Fig. S6, ESI $\dagger$ ). As a result, a Co-Co distance of 3.6268(3) $\AA$ is found between the central metal ions (Co1 and Co3), which is significantly shorter than the intramolecular Co-Co distances (i.e., Co1-Co2 $=5.2932(4)$ $\AA$; Co3-Co4 = 5.2981(4) ̊̊). This proximity between neighbouring molecules within the stacked array also leads to short Co-N contacts (3.2523(2)-3.2582(2) ̊) and other relatively close Co-Co interactions (5.6865(3), 5.7287(4) ̊̊). In addition to playing a pivotal role in the synthesis of the tri $v s$. hexanuclear complex, water also plays an important role in the formation of the extended stacks with two of the five water molecules in $\left[\mathrm{Co}_{3}{ }_{3}\left(\mathbf{P m}_{2} \mathrm{ImAm}\right)_{2} \mathbf{C l}_{4}\right] \cdot \mathbf{5 H}_{2} \mathrm{O}$ bound to three trinuclear complexes by a set of intra-stack hydrogen bonds (Fig. S6 and Table S3, ESI $\dagger$ ). The remaining three water molecules exist within the columnar packing arrangement of $\left[\mathrm{Co}_{3}{ }_{3}{ }_{(}\left(\mathbf{P m}_{2} \mathbf{I m A m}\right)_{2} \mathbf{C l}_{4}\right]$ in the extended solvent channels that are observed (Fig. S7, ESI $\dagger$ ), with the total volume of these channels being $17.5 \%$ of unit cell volume using a probe radius of $1.2 \AA$ in mercury. ${ }^{29}$ This is further supported by thermogravimetric analysis (Fig. S12, ESI $\dagger$ ). Although solvent voids exist between the columnar packing arrangement of $\left[\mathrm{Co}_{3}{ }_{3}\left(\mathbf{P m}_{2} \mathbf{I m A m}\right)_{2} \mathbf{C l}_{4}\right]$, a number of inter-stack interactions are present, primarily composed of weak $\mathrm{C}-\mathrm{H} \cdots \mathrm{Cl}$ hydrogen bonds (Table S3, ESI $\dagger$ ). Compared to intra-stack, the inter-stack interactions are much more limited, leading to Co-Co distances between columns that are much longer (e.g., $\geq 7.0704(4) \AA$; Tables S7 and S8, ESI $\dagger$ ).

Perhaps unsurprisingly, many similarities exist between the molecular structure of $\left[\mathrm{Co}^{\mathrm{II}}{ }_{6}(\boldsymbol{\mu}-\mathbf{C l})_{2}\left(\mathrm{Pm}_{2} \mathrm{ImAm}\right)_{4} \mathbf{C l}_{8}\right] \cdot \mathbf{2 C H}_{3} \mathrm{OH}$. $\mathbf{2 C H}_{\mathbf{2}} \mathbf{C l}_{\mathbf{2}}$ and $\left[\mathrm{Co}^{\mathrm{II}}{ }_{3}\left(\mathbf{P m}_{\mathbf{2}} \mathrm{ImAm}\right)_{\mathbf{2}} \mathbf{C l}_{\mathbf{4}}\right] \cdot \mathbf{5} \mathbf{H}_{\mathbf{2}} \mathrm{O}$. The former, which crystallizes in the monoclinic $P 2_{1} / c$ space group, may be considered as two linear trinuclear moieties similar to $\left[\mathbf{C o}_{3}{ }_{3}\left(\mathbf{P m}_{2} \mathbf{I m A m}\right)_{2} \mathbf{C l}_{4}\right]$ that are linked together through two bridging chloride ions (Fig. 1c). This leads to three unique cobalt centres and is consistent with the asymmetric unit of $\left[\mathrm{Co}_{6}{ }_{6}(\boldsymbol{\mu}-\mathrm{Cl})_{2}\left(\mathbf{P m}_{2} \mathrm{ImAm}\right)_{4} \mathrm{Cl}_{8}\right] \cdot 2 \mathrm{CH}_{3} \mathbf{O H} \cdot 2 \mathbf{C H}_{2} \mathbf{C l}_{2}$, which is located about a point of inversion. Within the asymmetric unit, the central Co ion (Co1) is pentacoordinate, bound to two anionic $\mathbf{P m}_{2} \mathbf{I m A m}$ ligands in a bidentate fashion with a bridging chloride ion completing the coordination environment. As revealed by $\mathrm{SHAPE}^{26}$ analysis, the geometry of this central cobalt ion is best described as nearly ideal square pyramidal (Table S12 and Fig. S11, ESI $\dagger$ ), with a longer $\mathrm{Co}-\mathrm{Cl}$ bond (2.628(3) $\AA$ ) when compared to the other Co-Cl bonds (2.286(2)-2.298(3) $\AA$ ) within this complex. The change in geometry from square planar to square pyramidal results in elongation of the $\mathrm{Co}-\mathrm{N}$ distances in $\left[\mathrm{Co}_{6}{ }_{6}(\mu-\mathrm{Cl})_{2}\left(\mathbf{P m}_{2} \mathrm{ImAm}\right)_{4} \mathrm{Cl}_{8}\right] \cdot 2 \mathrm{CH}_{3} \mathrm{OH} \cdot 2 \mathbf{C H}_{2} \mathrm{Cl}_{2}(1.888(7)-1.918(7) \AA)$ 
compared to $\left[\mathbf{C o}^{\mathbf{I I}}{ }_{3}\left(\mathbf{P m}_{2} \mathbf{I m A m}\right)_{2} \mathbf{C l}_{4}\right] \cdot \mathbf{5 H}_{2} \mathbf{O} \quad$ (1.86509(13)1.88734(11) Å). Although the polynuclear complexes are rather similar, the differences between them can been seen in the overlay shown in Fig. S9 (ESI $\dagger$ ). Interestingly, the geometry of all three unique cobalt ions in $\left[\mathrm{Co}_{6}{ }_{6}(\boldsymbol{\mu}-\mathbf{C l})_{2}\left(\mathbf{P m}_{2} \mathbf{I m A m}\right)_{4} \mathbf{C l}_{8}\right]$. $2 \mathrm{CH}_{3} \mathbf{O H} \cdot \mathbf{2} \mathrm{CH}_{2} \mathbf{C l}_{2}$ is closer to square pyramidal than trigonal bipyramidal as indicated by the $\tau$ parameter $^{30}$ (i.e., $0.01,0.09$ and 0.14 for $\mathrm{Co} 1, \mathrm{Co} 2$ and $\mathrm{Co} 3$, respectively). It is worth mentioning that $\mathrm{SHAPE}^{26}$ analysis also reveal these three cobalt centers as being closer to square pyramidal than trigonal bipyramidal (Fig. S11, ESI $\dagger$ ). The interplanar distance between the ligands with bridging groups within the hexanuclear complex is very short (3.082(12) $\AA$ ), resulting in $\pi-\pi$ interactions between the pyrimidyl rings of the $\mathbf{P m}_{2} \mathbf{I m A m}$ ligand coordinated to Co3.

Crystal packing of $\left[\mathrm{Co}_{6}{ }_{6}(\boldsymbol{\mu}-\mathrm{Cl})_{2}\left(\mathbf{P m}_{2} \mathrm{ImAm}\right)_{4} \mathbf{C l}_{8}\right] \cdot 2 \mathrm{CH}_{3} \mathrm{OH}$. $\mathbf{2 C H}_{2} \mathbf{C l}_{2}$ is composed of a brick-like array of hexanuclear complexes (Fig. S8, ESI $\dagger$ ), that are connected by weak $\mathrm{C}-\mathrm{H} \cdots \mathrm{Cl}$ hydrogen bonds (Table S3, ESI $\dagger$ ). Within the supramolecular structure, two crystallographically independent solvent molecules were refined (i.e., $\mathrm{CH}_{2} \mathrm{Cl}_{2}$ and $\mathrm{CH}_{3} \mathrm{OH}$ ). While dichloromethane is disordered and occupies a solvent void, methanol molecules act as a hydrogen bond acceptor from the imino hydrogen atoms of one complex and a hydrogen bond donor to a chloride ion in a neighbouring molecule in the plane below. Here, $\mathrm{CH}_{3} \mathrm{OH}$ plays a similar role to water in $\left[\mathrm{Co}_{3}{ }_{3}\left(\mathbf{P m}_{2} \operatorname{ImAm}\right)_{2} \mathbf{C l}_{4}\right] \cdot 5 \mathbf{H}_{2} \mathbf{O}$, although in this case it acts as a hydrogen donor to only one complex instead two. Dichloromethane has a Cl-Co contact with Co1, which is equal to 3.314(7) $\AA$, and shorter than the sum of van der Waals radii of cobalt and chlorine. ${ }^{31,32}$ The shortest Co-Co distance in $\left[\mathrm{Co}_{6}{ }_{6}(\boldsymbol{\mu}-\mathbf{C l})_{2}\left(\mathbf{P m}_{2} \mathrm{ImAm}\right)_{4} \mathbf{C l}_{8}\right] \cdot 2 \mathrm{CH}_{3} \mathbf{O H} \cdot \mathbf{2 C H}_{2} \mathbf{C l}_{2}$ is 4.1544(17) $\AA$ (Co1-Co3), which is longer than that found in $\left[\mathrm{Co}_{3}{ }_{3}\left(\mathbf{P m}_{2} \mathrm{ImAm}\right)_{2} \mathbf{C l}_{4}\right] \cdot \mathbf{5 H}_{2} \mathbf{O} \quad(3.6268(3) \AA)$. This is to be expected due to the chloride bridging ions separating the planar trinuclear fragments in $\left[\mathrm{Co}_{6}{ }_{6}(\mu-\mathbf{C l})_{2}\left(\mathbf{P m}_{2} \mathbf{I m A m}\right)_{4} \mathbf{C l}_{8}\right]$, which are not present in $\left[\mathrm{Co}^{\mathbf{I I}}{ }_{3}\left(\mathbf{P m}_{2} \mathbf{I m A m}\right)_{2} \mathbf{C l}_{4}\right]$ allowing for close association between the central $\mathrm{Co}^{\mathrm{II}}$ ions between neighbouring molecules. The distance between the central (Co1) and the outer ( $\mathrm{Co} 2$ and $\mathrm{Co} 3$ ) cobalt ions are essentially the same (5.2969(17) and 5.2881(16) ^, respectively), and are comparable to the values found in $\left[\mathrm{Co}^{\mathbf{I I}}{ }_{3}\left(\mathbf{P m}_{2} \operatorname{ImAm}\right)_{2} \mathbf{C l}_{4}\right] \cdot \mathbf{5 H}_{2} \mathbf{O}$. As well, a number of close intermolecular Co-Co interactions are present in $\left[\mathrm{Co}_{6}{ }_{6}(\mu-\mathrm{Cl})_{2}\left(\mathbf{P m}_{2} \mathrm{ImAm}\right)_{4} \mathbf{C l}_{8}\right] \cdot \mathbf{2} \mathrm{CH}_{3} \mathbf{O H} \cdot \mathbf{2 C H}_{2} \mathbf{C l}_{2}$, the shortest being 6.628(2) A. A comprehensive list of Co-Co distances can be found in Tables S9 and S10 (ESI $\dagger$ ).

To investigate the magnetic behaviour of both $\left[\mathrm{Co}_{3}{ }_{3}\left(\mathrm{Pm}_{2} \mathrm{ImAm}\right)_{2} \mathrm{Cl}_{4}\right] \cdot 5 \mathrm{H}_{2} \mathrm{O}$ and $\left[\mathrm{Co}_{6}{ }_{6}(\mu-\mathrm{Cl})_{2}\left(\mathrm{Pm}_{2} \mathrm{ImAm}\right)_{4} \mathrm{Cl}_{6}\right]$. ${ }_{2} \mathrm{CH}_{3} \mathbf{O H} \cdot 2 \mathbf{C H}_{2} \mathbf{C l}_{2}$, variable-temperature magnetic susceptibility data was collected on polycrystalline samples. For comparative purposes, magnetic susceptibility studies were also performed on $\left[\mathrm{Co}^{\text {II }}\left(\mathbf{P y}_{2} \mathbf{I m A m}\right)_{2}\right]$, revealing a $\chi T$ product of $0.48 \mathrm{~cm}^{3} \mathrm{~K} \mathrm{~mol}^{-1}$ at room temperature (Fig. S13, ESI $\dagger$ ). This value is larger than what is expected for low spin $\mathrm{Co}^{\mathrm{II}}$ from the spin-only formalism ( $C=0.375 \mathrm{~cm}^{3} \mathrm{~K} \mathrm{~mol}^{-1}$; assuming $\left.g=2\right)$ indicating a $g$ value around 2.26(5). Upon lowering the temperature, the $\chi T$ product remains relatively constant until $10 \mathrm{~K}$, where a decrease in the $\chi T$ product is observed until it reaches $0.43 \mathrm{~cm}^{3} \mathrm{~K} \mathrm{~mol}^{-1}$ at $1.9 \mathrm{~K}$. This decrease at low temperature is likely due to very weak antiferromagnetic (AF) intermolecular interactions between spin-carriers estimated at $-0.13 \mathrm{~K}$ from a Curie-Weiss fit $\left(\theta=2 z J S(S+1) / 3 k_{\mathrm{B}}=-0.26 \mathrm{~K}, z=4\right)$. The field dependence of the magnetization is also in good agreement with a low $\operatorname{spin} S=1 / 2$ configuration of the $\mathrm{Co}^{\mathrm{II}}$ centre (Fig. S14, ESI $\dagger$ ), as confirmed via fitting to the $S=1 / 2$ Brillouin function, which affords a consistent $g$-factor of 2.16(5).

Given the above information, the variable temperature magnetic susceptibility of the polynuclear complexes were analyzed (Fig. 2). For $\left[\mathrm{Co}_{3}{ }_{3}\left(\mathbf{P m}_{2} \mathbf{I m A m}\right)_{2} \mathbf{C l}_{4}\right] \cdot \mathbf{5} \mathbf{H}_{2} \mathbf{O}$, the $\chi T$ product at room temperature is around $5.2 \mathrm{~cm}^{3} \mathrm{~K} \mathrm{~mol}^{-1}$, which corresponds well to one $S=1 / 2 \mathrm{Co}^{\mathrm{II}}$ unit similar to [Co $\mathbf{C o}^{\mathrm{II}}\left(\mathbf{P y}_{2} \mathbf{I m A m}\right)_{2}$ ] (cf. $0.48 \mathrm{~cm}^{3} \mathrm{~K} \mathrm{~mol}^{-1}$ ) and two high spin $S=3 / 2 \mathrm{Co}^{\mathrm{II}}$ centers with $C=2.36 \mathrm{~cm}^{3} \mathrm{~K} \mathrm{~mol}^{-1}$, thus $g \approx 2.24(5) .{ }^{33}$ Magnetic coupling between the central (low spin $\mathrm{Co}^{\mathrm{II}}$ ) and peripheral (high spin $\mathrm{Co}^{\mathrm{II}}$ ) metal ion spins appears to be antiferromagnetic (AF), with a decrease of the $\chi T$ product down $4.4 \mathrm{~cm}^{3} \mathrm{~K} \mathrm{~mol}^{-1}$ at about $56 \mathrm{~K}$ (Fig. 2 inset). It should be noted that the intrinsic spin-orbit coupling of high spin octahedral $\mathrm{Co}(\mathrm{II})$ metal ions ${ }^{33}$ could also explain in part the $\chi T$ decrease in this temperature range. As a result of the intramolecular AF coupling, the $\chi T$ increase at lower temperatures is likely due to the non-compensation of the spin and stabilization of an $S_{\mathrm{T}}=5 / 2$ ground state. However, this simple description is not supported by the $\chi T$ product of $15.4 \mathrm{~cm}^{3} \mathrm{~K} \mathrm{~mol}^{-1}$ that is reached at $1.85 \mathrm{~K}$, which is neither compatible with an $S_{\mathrm{T}}=5 / 2\left(C=4.375 \mathrm{~cm}^{3} \mathrm{~K} \mathrm{~mol}^{-1}\right)$ nor an $S_{\mathrm{T}}=7 / 2\left(C=7.875 \mathrm{~cm}^{3} \mathrm{~K} \mathrm{~mol}^{-1}\right)$ ground state expected for intra-complex antiferromagnetic or ferromagnetic interactions, respectively. Therefore, the presence of intermolecular magnetic interactions which align the macro-spin, $S_{\mathrm{T}}$, of the trinuclear complexes is necessary to explain the magnetic data below $50 \mathrm{~K}$. With very close Co-Co interactions between neighboring molecules (3.6268(3) ̊), along with a number of intra-stack and inter-stack Co-Co interactions (see Tables S7 and S8, ESI $\dagger$ ), it is difficult to assign specific interactions that dominate the

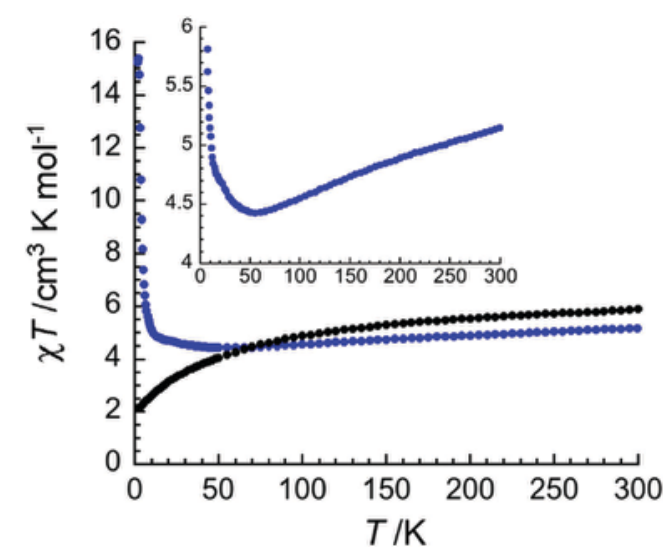

Fig. 2 Temperature dependence of the $\chi^{T}$ product at $0.1 \mathrm{~T}$ (where $\chi$ is defined as the magnetic susceptibility equal to $M / H$ per mole of $\left\{\mathrm{Co}_{3}{ }_{3}\left(\mathrm{Pm}_{2} \mathrm{ImAm}\right)_{2} \mathrm{Cl}_{4}\right\}$ unit) for $\left[\mathrm{Co}_{3}\left(\mathrm{Pm}_{2} \mathrm{ImAm}\right)_{2} \mathrm{Cl}_{4}\right] \cdot 5 \mathrm{H}_{2} \mathrm{O}$ (in blue) and $\left[\mathrm{Co}_{6}{ }_{6}(\mu-\mathrm{Cl})_{2}\left(\mathrm{Pm}{ }_{2} \mathrm{ImAm}\right)_{4} \mathrm{Cl}_{6}\right] \cdot 2 \mathrm{CH}_{3} \mathrm{OH} \cdot 2 \mathrm{CH}_{2} \mathrm{Cl}_{2}$ (in black). 
magnetic exchange. Nevertheless, it is important to note that the inter-complex interactions could be antiferromagnetic between the different types of Co spins (i.e., central and peripheral metal ion exchange interactions) or ferromagnetic between similar ones; however, the nature of the supramolecular packing and degree of intermolecular interactions, mitigates the effectiveness of extracting exchange couplings based on a particular fit function. Nonetheless, the $M v s$. $H$ data have been measured between 1.85 and $8 \mathrm{~K}$ and, even at $7 \mathrm{~T}$, the magnetization does not saturate, reaching a value of $3.5 \mu_{\mathrm{B}}$ supporting an $S_{\mathrm{T}}=5 / 2$ ground state rather than $S_{\mathrm{T}}=7 / 2$ (Fig. S15, ESI $\dagger$ ). Furthermore, it is worth noting that the S-shaped curve observed around 1.5 T further suggests the presence of weak antiferromagnetic interactions between complexes. In addition, ac susceptibility measurements were also performed on $\left[\mathrm{Co}^{\mathrm{II}}{ }_{3}\left(\mathbf{P m}_{\mathbf{2}} \mathrm{ImAm}\right)_{2} \mathbf{C l}_{4}\right] \cdot \mathbf{5 H}_{2} \mathrm{O}$, however, even under an applied static field up to $1 \mathrm{~T}$, an out-of-phase ac susceptibility signal was not detected above $1.8 \mathrm{~K}$ between 0.1 and $10000 \mathrm{~Hz}$.

In the case of $\left[\mathrm{Co}_{6}{ }_{6}(\mu-\mathrm{Cl})_{2}\left(\mathrm{Pm}_{2} \mathrm{ImAm}\right)_{4} \mathrm{Cl}_{6}\right] \cdot 2 \mathrm{CH}_{3} \mathrm{OH} \cdot 2 \mathrm{CH}_{2} \mathrm{Cl}_{2}$, the $\chi T$ product at $300 \mathrm{~K}$ is approximately $5.8 \mathrm{~cm}^{3} \mathrm{~K} \mathrm{~mol}^{-1}$ (per $\left\{\mathrm{Co}_{3}{ }_{3}\left(\mathrm{Pm}_{2} \mathrm{ImAm}\right)_{2} \mathrm{Cl}_{4}\right\}$ unit) which corresponds to one $S=$ $1 / 2 \mathrm{Co}^{\text {II }}$ moiety similar to $\left[\mathbf{C o}^{\text {II }}\left(\mathbf{P y}_{2} \mathbf{I m A m}\right)_{2}\right]\left(c f .0 .48 \mathrm{~cm}^{3} \mathrm{~K} \mathrm{~mol}^{-1}\right)$ and two high spin $S=3 / 2 \mathrm{Co}^{\mathrm{II}}$ centers with $C=2.66 \mathrm{~cm}^{3} \mathrm{~K} \mathrm{~mol}^{-1}$ and therefore a $g$-value of 2.38(5) (Fig. 2). ${ }^{33}$ Similar to $\left[\mathrm{Co}_{3}{ }_{3}\left(\mathbf{P m}_{2} \mathbf{I m A m}\right)_{2} \mathbf{C l}_{4}\right] \cdot \mathbf{5 H}_{2} \mathbf{O}$, coupling between the two types of metal ions (i.e., the central low spin $\mathrm{Co}^{\mathrm{II}}$ and peripheral high spin $\mathrm{Co}^{\mathrm{II}}$ ) appears to be antiferromagnetic, with a decrease of the $\chi T$ product down $2.1 \mathrm{~cm}^{3} \mathrm{~K} \mathrm{~mol}^{-1}$ at $1.85 \mathrm{~K}$ and $0.1 \mathrm{~T}$ for $\left[\mathrm{Co}_{6}^{\mathrm{II}}(\boldsymbol{\mu}-\mathrm{Cl})_{2}\left(\mathrm{Pm}_{2} \mathrm{ImAm}\right)_{4} \mathrm{Cl}_{6}\right] \cdot 2 \mathrm{CH}_{3} \mathrm{OH} \cdot \mathbf{2 C H}_{2} \mathbf{C l}_{2}$. As in $\left[\mathrm{Co}_{3}{ }_{3}\left(\mathbf{P m}_{2} \mathbf{I m A m}\right)_{2} \mathbf{C l}_{\mathbf{4}}\right] \cdot \mathbf{5} \mathbf{H}_{2} \mathbf{O}$ (vide supra), the presence of a significant spin-orbit coupling could also explain in part the $\chi T$ decrease. Nevertheless, this simple description is not supported by the $\chi T$ product of $2.1 \mathrm{~cm}^{3} \mathrm{~K} \mathrm{~mol}^{-1}$ that is reached at $1.85 \mathrm{~K}$. This value is not compatible with one $S_{\mathrm{T}}=5 / 2$ units $(C=$ $4.375 \mathrm{~cm}^{3} \mathrm{~K} \mathrm{~mol}^{-1}$ ) expected for intra-complex antiferromagnetic interactions. Therefore, the presence of magnetic interactions through the chlorine bridge or/and the presence of effective $S=1 / 2$ spins at low temperature on the peripherical Co sites, might explain the reduced dc-susceptibility. The $M v s$. $H$ data have also been measured between 1.85 and $8 \mathrm{~K}$ (Fig. S16, $\mathrm{ESI} \dagger)$. At $7 \mathrm{~T}$, the magnetization does not saturate reaching a value of $3.2 \mu_{\mathrm{B}}$, which is close to what was found for $\left[\mathrm{Co}_{3}{ }_{3}\left(\mathrm{Pm}_{2} \mathrm{ImAm}\right)_{2} \mathrm{Cl}_{4}\right] \cdot 5 \mathrm{H}_{2} \mathrm{O}$ (Fig. S15, ESI $\dagger$ ).

In contrast to $\left[\mathrm{Co}_{3}{ }_{3}\left(\mathbf{P m}_{2} \mathbf{I m A m}\right)_{2} \mathbf{C l}_{4}\right] \cdot 5 \mathrm{H}_{2} \mathrm{O}$, an out-of-phase signal was observed for $\left[\mathrm{Co}_{6}{ }_{6}(\boldsymbol{\mu}-\mathrm{Cl})_{2}\left(\mathbf{P m}_{2} \mathrm{ImAm}\right)_{4} \mathrm{Cl}_{6}\right] \cdot \mathbf{2} \mathrm{CH}_{3} \mathbf{O H} \cdot \mathbf{2 C H}_{2} \mathbf{C l}_{2}$ when ac susceptibility measurements were performed under an applied dc field at $1.9 \mathrm{~K}$ (Fig. S17, ESI $\dagger$ ). Although no ac signal was detected under zero dc field, upon application of increasingly higher fields a clear relaxation mode begins to appear. This behavior is commonly observed in cases where the magnetic relaxation is influenced by quantum tunneling of the magnetization (QTM). ${ }^{34,35}$ Subsequently, ac measurements were performed under an optimal static dc field of $0.1 \mathrm{~T}$, which revealed a frequency and temperature dependent relaxation mode, indicating unambiguously slow dynamics of the magnetization of $\left[\mathbf{C o}_{6}{ }_{6}(\mu-\mathbf{C l})_{2}\left(\mathbf{P m}_{2} \operatorname{ImAm}\right)_{4} \mathbf{C l}_{6}\right]$.

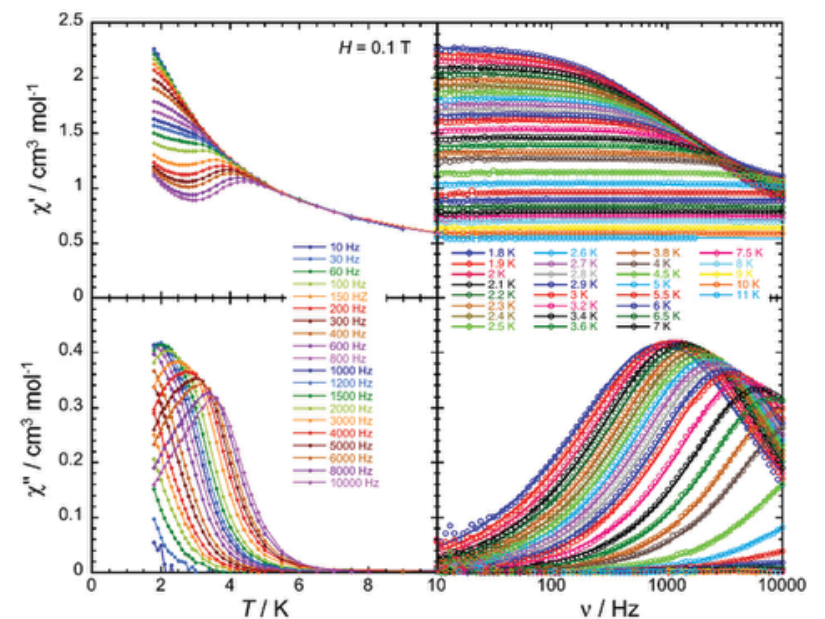

Fig. 3 Temperature (left) and ac frequency (right) dependences of the real $\left(\chi^{\prime}\right.$, top) and imaginary $\left(\chi^{\prime \prime}\right.$, bottom) parts of the ac susceptibility, between 1.85 and $10 \mathrm{~K}$ and between 10 and $10000 \mathrm{~Hz}$, for [Co" ${ }_{6}(\boldsymbol{\mu}$ $\left.\mathrm{Cl})_{2}\left(\mathrm{Pm}_{2} \mathrm{ImAm}\right)_{4} \mathrm{Cl}_{6}\right] \cdot 2 \mathrm{CH}_{3} \mathrm{OH} \cdot 2 \mathrm{CH}_{2} \mathrm{Cl}_{2}$ in a $0.1 \mathrm{~T}$ dc field. Solid lines are visual guides on the left plots while they show the generalized Debye fit of the ac data on the right.

$2 \mathbf{C H}_{3} \mathbf{O H} \cdot 2 \mathbf{C H}_{2} \mathbf{C l}_{2}$ (Fig. 3) and thus its Single-Molecule Magnet (SMM) properties.

The analysis of the field and temperature dependence of the relaxation time ( $\tau$; Fig. 4) should start by calculating the standard deviations on the obtained values. Based on the illuminating work of N. Chilton and D. Reta, ${ }^{36}$ the estimated standard deviations (ESD) of the relaxation time can be determined easily from the generalized Debye fits of the experimental data (Fig. 3 and Fig. S17, ESI $\dagger$ ) and the obtained $\alpha$ parameter (Fig. S18 and S19, ESI $\dagger$ ), which quantify the broadness of the relaxation time distribution. As shown in Fig. 4, the obtained ESD are large and thus the following analysis of the relaxation must be taken with caution and certainly as a qualitative description.

To explain paramagnetic relaxations, ${ }^{37}$ four main mechanisms are usually involved, which include Raman, ${ }^{38}$ direct, ${ }^{37}$

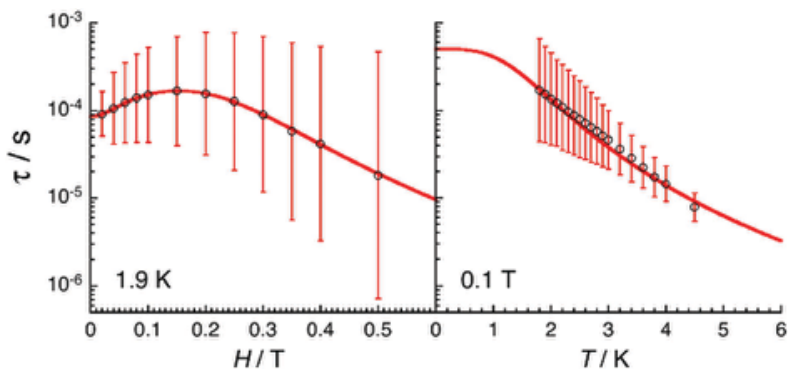

Fig. 4 Dc-field (left) and temperature (right) dependences of the relaxation time for $\left[\mathrm{Co}_{6}{ }_{6}\left(\mu-\mathrm{Cl}_{2}\left(\mathrm{Pm}_{2} \mathrm{ImAm}\right)_{4} \mathrm{Cl}_{6}\right] \cdot \mathbf{2} \mathrm{CH}_{3} \mathrm{OH} \cdot \mathbf{2} \mathrm{CH}_{2} \mathrm{Cl}_{2}\right.$ estimated from the generalized Debye fits of the ac susceptibility data shown in Fig. S17 (ESI $\dagger$ ) and Fig. 3 collected at $1.9 \mathrm{~K}$ and under an $0.1 \mathrm{~T}$ applied field, respectively. The estimated standard deviations of the relaxation time (vertical solid bars) have been calculated from the $\alpha$ parameters of the generalized Debye fit (Fig. S18 and S19, ESI $\dagger$ ) and the log-normal distribution as described in ref. 35. The solid red lines are the best fit discussed in the text. 
thermally activated (Arrhenius) ${ }^{38}$ and QTM $^{39,40}$ relaxation processes, as summarized in the following equation: ${ }^{39}$

$$
\begin{gathered}
\tau^{-1}=\tau_{\text {Raman }}{ }^{-1}+\tau_{\text {direct }}{ }^{-1}+\tau_{\text {Arrhenius }}{ }^{-1}+\tau_{\mathrm{QTM}}{ }^{-1} \\
\tau^{-1}=C \frac{1+C_{1} H^{2}}{1+C_{2} H^{2}} T^{n}+A T H^{4}+\tau_{0}^{-1} \exp \left(-\frac{\Delta}{k_{\mathrm{B}} T}\right)+\frac{B_{1}}{1+B_{2} H^{2}}
\end{gathered}
$$

As shown by this equation, each relaxation has its own characteristic temperature $(T)$ and dc-field $(H)$ dependence. Considering the field dependence of the relaxation time (left part of Fig. 4), it should be noted first that the $\tau$ increase below $0.15 \mathrm{~T}$ agrees with only QTM or Raman (with $C_{2}>C_{1}$ ) processes, while at higher fields, the $H^{4}$ variation strongly suggest a direct relaxation mechanism. Therefore, the $\tau$ vs. $H$ data have been fit by two simple models including (i) Raman \& direct and (ii) QTM \& direct processes but only when the three mechanisms are considered the field and temperature dependence of the relaxation time can be satisfactory fitted (Fig. 4; with $A=4(1) \times 10^{5} \mathrm{~K}^{-1} \mathrm{~T}^{-4} \mathrm{~s}^{-1}, B_{1}=$ $6920(200) \mathrm{s}^{-1}, B_{2}=260(30) \mathrm{T}^{-2}, C=433(50) \mathrm{K}^{-3.7} \mathrm{~s}^{-1}, C_{1}=C_{2}$ set to 0 and $n=3.7(5))$. It is worth mentioning that different models including an Arrhenius relaxation did not improve significantly the fitting agreement. As mentioned above, even if this analysis should be taken with a great caution, it suggests that QTM, Raman and direct processes are responsible for the observed SMM properties in $\left[\mathrm{Co}_{6}{ }_{6}(\mu-\mathrm{Cl})_{2}\left(\mathrm{Pm}_{2} \mathrm{ImAm}\right)_{4} \mathrm{Cl}_{6}\right] \cdot 2 \mathrm{CH}_{3} \mathrm{OH} \cdot 2 \mathrm{CH}_{2} \mathrm{Cl}_{2}$.

By tapping into the rich ligating affinity of $\mathrm{N}$-imidoylamidine ligands, we have prepared a family of cobalt complexes in which both nuclearity and topology may be controlled. This was achieved through judicious choice of the cobalt salt employed and meticulous control of the solvent conditions, thereby enabling selective isolation of mono-, tri- and hexanuclear cobalt complexes. In the case of the latter two materials, where coordination occurs in both the bidentate and tridentate sites within the $\mathrm{N}$-imidoylamidine ligands, the nuclearity is determined through careful control of the hydration at the ppm level (e.g., $10000 v s .300 \mathrm{ppm})$. The spin states of the cobalt ions in these complexes were elucidated by magnetic susceptibility measurements, which reveal a unique combination of low and high spin states for the $\mathrm{Co}^{\mathrm{II}}$ ions within the $\left\{\mathrm{Co}_{3}{ }_{3}\right\}$ aggregates. This study demonstrates the versatility of this ligand framework, affording an ideal platform in the development of polynuclear complexes. Furthermore, this design strategy provides an avenue towards achieving tailormade polynuclear homo and heterometallic complexes, and enables the exploration of polynuclear species with differing spin states.

\section{Acknowledgements}

This work was supported by the University of Ottawa, the Canadian Foundation for Innovation, the National Sciences and Engineering Council of Canada and the Ontario Research Fund. J. L. B. is grateful to the Ontario Ministry of Research and Innovation for an Early Researcher Award. R. C. thanks CONACYT for graduate student scholarship. The University of Bordeaux, the Region Nouvelle Aquitaine, the CNRS, the GdR MCM-2 and the MOLSPIN COST action CA15128 are also acknowledged for financial support.

1 U. R. Pokharel, F. R. Fronczek and A. W. Maverick, Nat. Commun., 2014, 5, 5883.

2 N. Kaeffer, M. Chavarot-Kerlidou and V. Artero, Acc. Chem. Res., 2015, 48, 1286-1295.

3 T. B. Boit, N. A. Weires, J. Kim and N. K. Garg, ACS Catal., 2018, 8, 1003-1008.

4 M. N. Kopylovich, J. Lasri, M. F. C. Guedes da Silva and A. J. L. Pombeiro, Dalton Trans., 2009, 3074-3084.

5 T. Jurca, A. Farghal, P.-H. Lin, I. Korobkov, M. Murugesu and D. S. Richeson, J. Am. Chem. Soc., 2011, 133, 15814-15817.

6 F. Habib, O. R. Luca, V. Vieru, M. Shiddiq, I. Korobkov, S. I. Gorelsky, M. K. Takase, L. F. Chibotaru, S. Hill, R. H. Crabtree and M. Murugesu, Angew. Chem., Int. Ed., 2013, 52, 11290-11293.

7 J. D. Harris, M. J. Moran and I. Aprahamian, Proc. Natl. Acad. Sci. U. S. A., 2018, 115, 9414-9422.

8 M. N. Kopylovich and A. J. L. Pombeiro, Coord. Chem. Rev., 2011, 255, 339-355.

9 M. M. Turnbull, M. Y. Wei and R. D. Willett, J. Coord. Chem., 1995, 35, 11-17.

10 R. Boča, M. Hvastijová, J. Kožíšek and M. Valko, Inorg. Chem., 1996, 35, 4794-4797.

11 M.-L. Tong, Y.-M. Wu, Y.-X. Tong, X.-M. Chen, H.-C. Chang and S. Kitagawa, Eur. J. Inorg. Chem., 2003, 2385-2388.

12 A. Igashira-Kamiyama, T. Kajiwara, T. Konno and T. Ito, Inorg. Chem., 2006, 45, 6460-6466.

13 A. A. Starikova, Chem. Pap., 2018, 72, 821-828.

14 T. Kajiwara, A. Kamiyama and T. Ito, Chem. Commun., 2002, 1256-1257.

15 T. Glaser, H. Theil, I. Liratzis, T. Weyhermüller and E. Bill, Inorg. Chem., 2006, 45, 4889-4891.

16 M. N. Kopylovich, A. M. Kirillov, E. A. Tronova, M. Haukka, V. Y. Kukushkin and A. J. L. Pombeiro, Eur. J. Inorg. Chem., 2010, 2425-2432.

17 V. Duros, H. Sartzi, S. J. Teat, Y. Sanakis, O. Roubeau and S. P. Perlepes, Inorg. Chem. Commun., 2014, 50, 117-121.

18 A. A. Leitch, I. Korobkov, A. Assoud and J. L. Brusso, Chem. Commun., 2014, 50, 4934-4936.

19 M. Yousaf, N. J. Yutronkie, R. Castañeda, J. A. Klein and J. Brusso, New J. Chem., 2017, 41, 12218-12224.

20 R. Castañeda, A. Hollingshead, B. Gabidullin and J. L. Brusso, Cryst. Growth Des., 2017, 17, 6572-6578.

21 R. Castañeda, K. L. M. Harriman, J. W. L. Wong, B. Gabidullin, M. Murugesu and J. L. Brusso, Eur. J. Inorg. Chem., 2019, 963-972. 
22 D. M. Jenkins, A. J. Di Bilio, M. J. Allen, T. A. Betley and J. C. Peters, J. Am. Chem. Soc., 2002, 124, 15336-15350.

23 M. P. Marshak, M. B. Chambers and D. G. Nocera, Inorg. Chem., 2012, 51, 11190-11197.

24 N. Leconte, B. Baptiste, C. Philouze and F. Thomas, Dalton Trans., 2018, 47, 11303-11307.

25 A. M. Whyte, Y. Shuku, G. S. Nichol, M. M. Matsushita, K. Awaga and N. Robertson, J. Mater. Chem., 2012, 22, 17967-17975.

26 D. Casanova, M. Llunell, P. Alemany and S. Alvarez, Chem. Eur. J., 2005, 11, 1479-1494.

27 A. Świtlicka, B. Machura, M. Penkala, A. Bieńko, D. C. Bieńko, J. Titiš, C. Rajnák, R. Boča, A. Ozarowski and M. Ozerov, Inorg. Chem., 2018, 57, 12740-12755.

28 R. F. Higgins, B. N. Livesay, T. J. Ozumerzifon, J. P. Joyce, A. K. Rappé and M. P. Shores, Polyhedron, 2018, 143, 193-200.

29 C. F. Macrae, I. J. Bruno, J. A. Chisholm, P. R. Edgington, P. McCabe, E. Pidcock, L. Rodriguez-Monge, R. Taylor, J. van de Streek and P. A. Wood, J. Appl. Crystallogr., 2008, 41, 466-470.
30 A. W. Addison, T. N. Rao, J. Reedijk, J. van Rijn and G. C. Verschoor, Dalton Trans., 1984, 1349-1356.

31 A. Bondi, J. Phys. Chem., 1964, 68, 441-451.

32 S. S. Batsanov, Inorg. Mater., 2001, 37, 871-885.

33 R. L. Carlin, Magnetochemistry, Springer, Berlin, 1986.

34 D. Gatteschi, R. Sessoli and J. Villain, Molecular Nanomagnets, Oxford University Press, 2006.

35 L. Lecren, W. Wernsdorfer, Y.-G. Li, O. Roubeau, H. Miyasaka and R. Clérac, J. Am. Chem. Soc., 2005, 127, 11311-11317.

36 D. Reta and N. F. Chilton, Phys. Chem. Chem. Phys., 2019, 21, 23567-23575.

37 K. N. Shrivastava, Phys. Status Solidi A, 1983, 117, 437-458. 38 J. H. Van Vleck, Phys. Rev., 1940, 57, 426-447.

39 A. Abragam and B. Bleaney, Electron Paramagnetic Resonance of Transition Ions, Dover, New York, 1986.

40 M. Ding, A. K. Hickey, M. Pink, J. Telser, D. L. Tierney, M. Amoza, M. Rouzières, T. J. Ozumerzifon, W. A. Hoffert, M. P. Shores, E. Ruiz, R. Clérac and J. M. Smith, Chem. - Eur. J., 2019, 25, 10625-10632. 
Supporting Information

\section{Controlling the nuclearity and topology of cobalt complexes through}

\section{hydration at the ppm level}

Raúl Castañeda, ${ }^{a}$ Mathieu Rouzières, ${ }^{b}$ Rodolphe Clérac $, *, b$ and Jaclyn L. Brusso*,a

a Department of Chemistry and Biomolecular Sciences, University of Ottawa, 150 Louis Pasteur, Ottawa, Ontario K1N 6N5, Canada.

b Univ. Bordeaux, CNRS, Centre de Recherche Paul Pascal, UMR 5031, 33600 Pessac, France

\section{Contents (19 pages)}

Page S2 Experimental section

Page S6 Crystal Structure Figures and Tables

Page S13 Shape Analysis

Page S15 Thermogravimetric Analysis

Page S16 Additional Magnetic Measurements

Page S20 References 


\section{Experimental Section}

General Procedures. All solvents and reagents were reagent grade and used without further purification. Bis(pyridinium) tetrachlorocobaltate(II) $\quad\left([\mathrm{PyH}]_{2}\left[\mathrm{CoCl}_{4}\right]\right), \quad \mathrm{N}$-2-pyridylimidoyl-2-pyridylamidine (Py2 $\mathbf{I m A m})$, and N-2-pyrimid ylimidoyl-2-pyrimidylamidine ( $\left.\mathrm{Pm}_{2} \mathrm{ImAm}\right)$ were synthesized according to the literature procedure reported earlier by us. ${ }^{1,2}$ IR spectra were recorded on an Agilent Technologies Cary 630 FT-IR spectrometer. Bulk purity was determined by comparison of powder XRD patterns with those calculated from the single crystal data (Figure S1-3).

Synthesis of [Co"(Py: ImAm) $)_{2}$. A degassed solution of cobalt(II) acetate tetrahydrate $(0.3969 \mathrm{~g}$, $1.59 \mathrm{mmol}$ ) in $8 \mathrm{~mL}$ dry DMF was added via syringe to a degassed solution of Py2 ImAm (0.7111 $\mathrm{g}, 3.15$ $\mathrm{mmol})$ in $60 \mathrm{~mL}$ anhydrous acetonitrile $\left(\mathrm{CH}_{3} \mathrm{CN}\right)$ and $10 \mathrm{~mL}$ triethyl amine $\left(\mathrm{Et}_{3} \mathrm{~N}\right)$ under continuous stirring. After stirring for $5 \mathrm{~min}$, the resulting orange solution was left to stand at RT. After three days, orange block-like crystals were collected and rinsed with methanol and hexanes. Yield: $0.6197 \mathrm{~g}$ (1.22 mmol, 76.6\%). IR (cm $\left.{ }^{-1}\right): 3252(\mathrm{~m}), 3051(\mathrm{w}), 1592(\mathrm{~m}), 1575(\mathrm{~m}), 1523(\mathrm{~m}), 1498(\mathrm{w}), 1470(\mathrm{~m})$, $1441(\mathrm{~s}), 1420(\mathrm{~m}), 1272(\mathrm{~m}), 1241(\mathrm{w}), 1065(\mathrm{~m}), 998(\mathrm{~m}), 947(\mathrm{w}), 845(\mathrm{~s}), 812(\mathrm{~m}), 755(\mathrm{~m}), 738(\mathrm{~s})$, 717 (s).

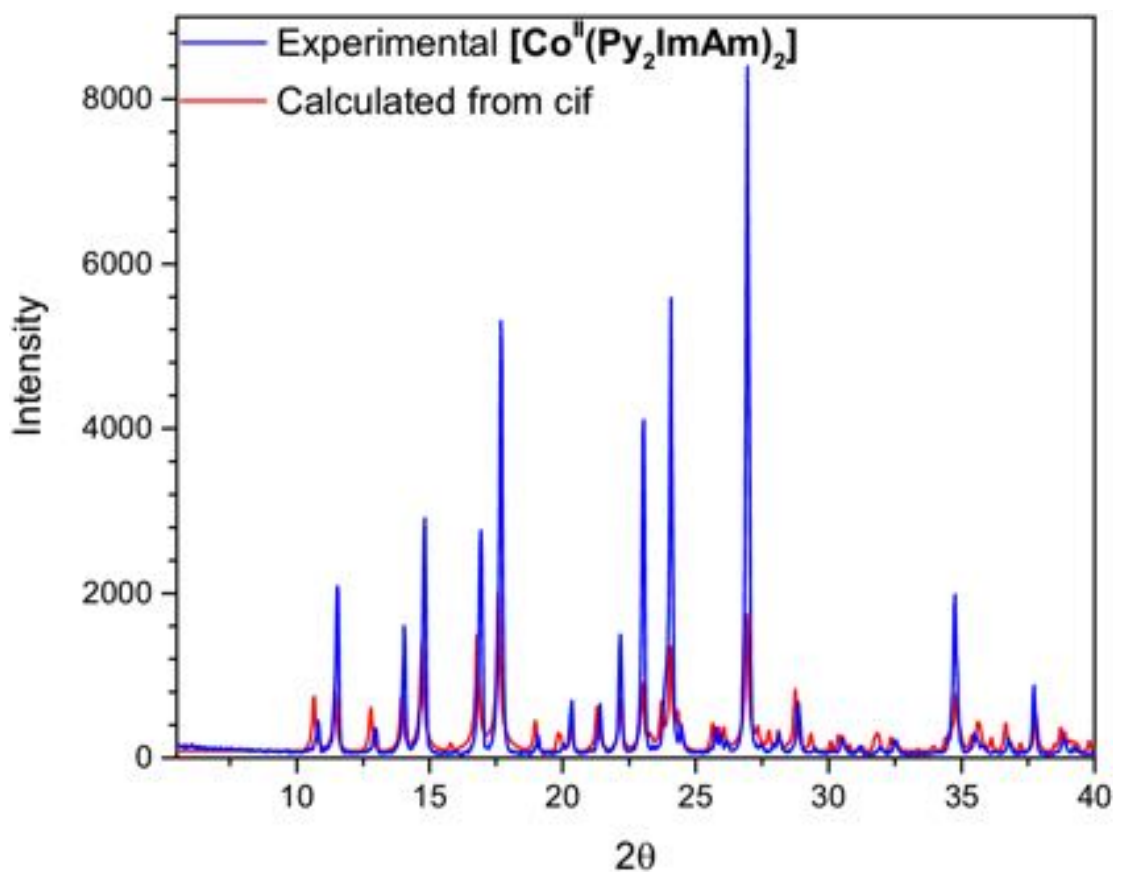

Figure S1. PXRD pattern overlay of experimental microcrystalline [Co"(Py. $\mathbf{I m A m})_{2}$ ] complex at room temperature with its calculated pattern from single crystal at $200 \mathrm{~K}$ using Mercury. ${ }^{3}$ 
Synthesis of $\left[\mathrm{Co}_{3}\left(\mathrm{Pm}_{2} \mathrm{ImAm}\right)_{2} \mathrm{Cl}_{4}\right] \cdot 5 \mathrm{H}_{2} \mathrm{O}$. A degassed solution of $\left[\mathrm{PyH}_{2}\left[\mathrm{CoCl}_{4}\right](0.4364 \mathrm{~g}, 1.21 \mathrm{mmol})\right.$ in $17 \mathrm{~mL}$ of $99 \%$ methanol was added via syringe to a degassed solution of Pm $\mathbf{I m A m}$ (0.1836 g, $0.81 \mathrm{mmol})$ in $17 \mathrm{~mL}$ of anhydrous $\mathrm{CH}_{2} \mathrm{Cl}_{2}$ under continuous stirring. After stirring for $5 \mathrm{~min}$, the resulting deep redblack solution was left to stand at room temperature. After two days, red plate-like crystals were filtered, rinsed with $4 \mathrm{~mL}$ of a $1: 1$ mixture of methanol and $\mathrm{CH}_{2} \mathrm{Cl}_{2}$, then left to dry in air. Yield: $0.1473 \mathrm{~g}(0.17$ mmol, 42.3\%). IR (cm $\left.{ }^{-1}\right): 3542(\mathrm{~m}), 3467(\mathrm{~m}), 3218(\mathrm{~s}), 3069(\mathrm{~m}), 1609(\mathrm{~m}), 1579(\mathrm{~m}), 1557(\mathrm{~s}), 1542(\mathrm{~m})$, 1489 (s), 1439 (w), 1407 (s), 1395 (s), $1321(\mathrm{~m}), 1287(\mathrm{~m}), 1273(\mathrm{~m}), 1195$ (w), $1099(\mathrm{~m}), 1056(\mathrm{~m}), 1015$ $(\mathrm{m}), 1005(\mathrm{~m}), 905(\mathrm{~s}), 830(\mathrm{~s}), 735(\mathrm{w}), 713(\mathrm{~s})$.

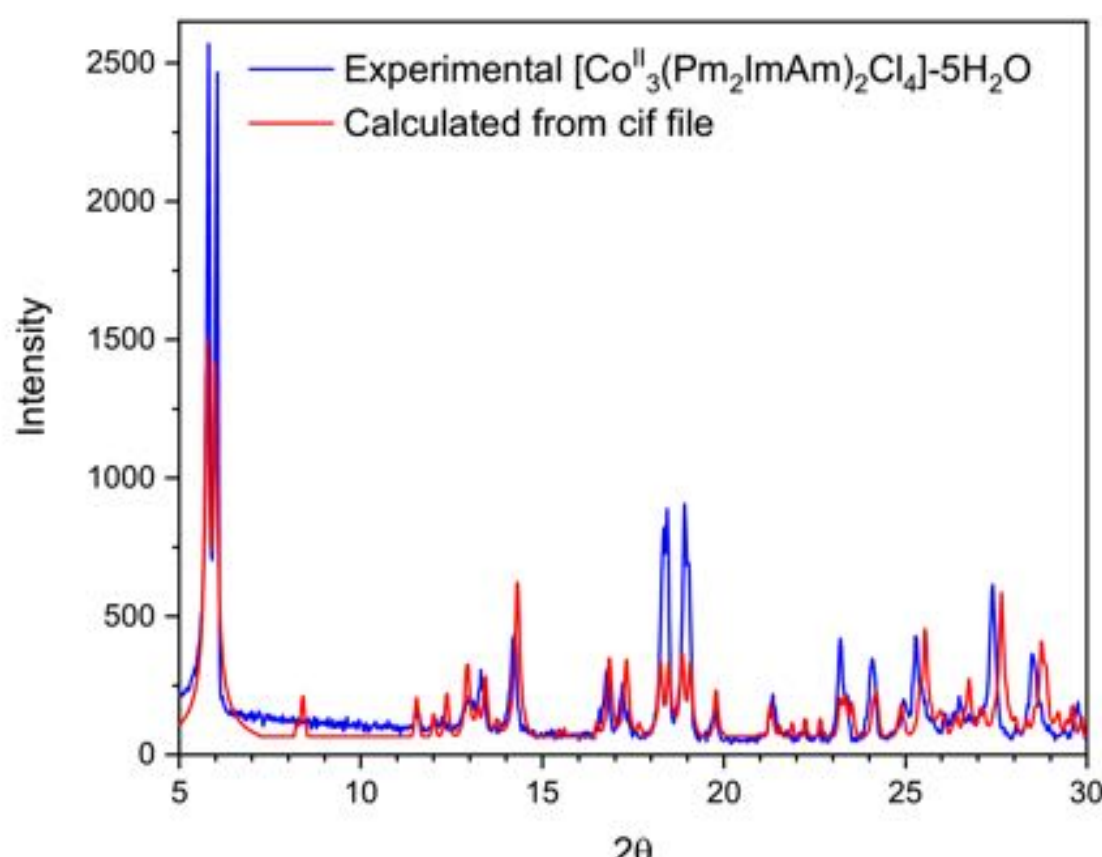

Figure S2. PXRD pattern overlay of experimental microcrystalline $\left[\mathrm{Co}_{3}{ }_{3}\left(\mathrm{Pm}_{2} \mathrm{ImAm}\right)_{2} \mathrm{Cl}_{4}\right] \cdot 5 \mathrm{H}_{2} \mathrm{O}$ trinuclear complex at room temperature with its calculated pattern from single crystal at $200 \mathrm{~K}$ using Mercury. ${ }^{3}$

Synthesis of $\left[\mathrm{Co}_{6}{ }_{6}(\mu-\mathrm{Cl})_{2}\left(\mathrm{Pm}_{2} \mathrm{ImAm}\right)_{4} \mathrm{Cl}_{6}\right] \cdot 2 \mathrm{CH}_{3} \mathrm{OH} \cdot 2 \mathrm{CH}_{2} \mathrm{Cl}_{2}$. A degassed solution of $[\mathrm{PyH}]_{2}\left[\mathrm{CoCl}_{4}\right]$ $(0.5671 \mathrm{~g}, 1.57 \mathrm{mmol})$ in $20 \mathrm{~mL}$ of $99.97 \%$ methanol was added via syringe to a degassed solution of Pm 2 ImAm (0.2363 g, $1.04 \mathrm{mmol}$ ) in $20 \mathrm{~mL}$ of anhydrous $\mathrm{CH}_{2} \mathrm{Cl}_{2}$. After stirring for 5 minutes, the resulting deep red-black solution was left to stand at room temperature. After two days, block-like black crystals were filtered, rinsed with $0.5 \mathrm{~mL}$ of a $1: 1$ mixture of anhydrous methanol and anhydrous $\mathrm{CH}_{2} \mathrm{Cl}_{2}$, then dried in air. Yield: $0.0929 \mathrm{~g}(0.22 \mathrm{mmol}, 20.1 \%) . \mathrm{IR}\left(\mathrm{cm}^{-1}\right)$ : $3423(\mathrm{~m}), 3268(\mathrm{w}), 3220(\mathrm{~m}), 3059(\mathrm{w}), 1605$ 
(w), 1554 (s), $1474(s), 1439(w), 1394(s), 1308$ (w), $1272(m), 1231(w), 1190(w), 1093(m), 1053(m)$, $1016(w), 1003(m), 865(m), 831(s), 739(w), 708(s)$.

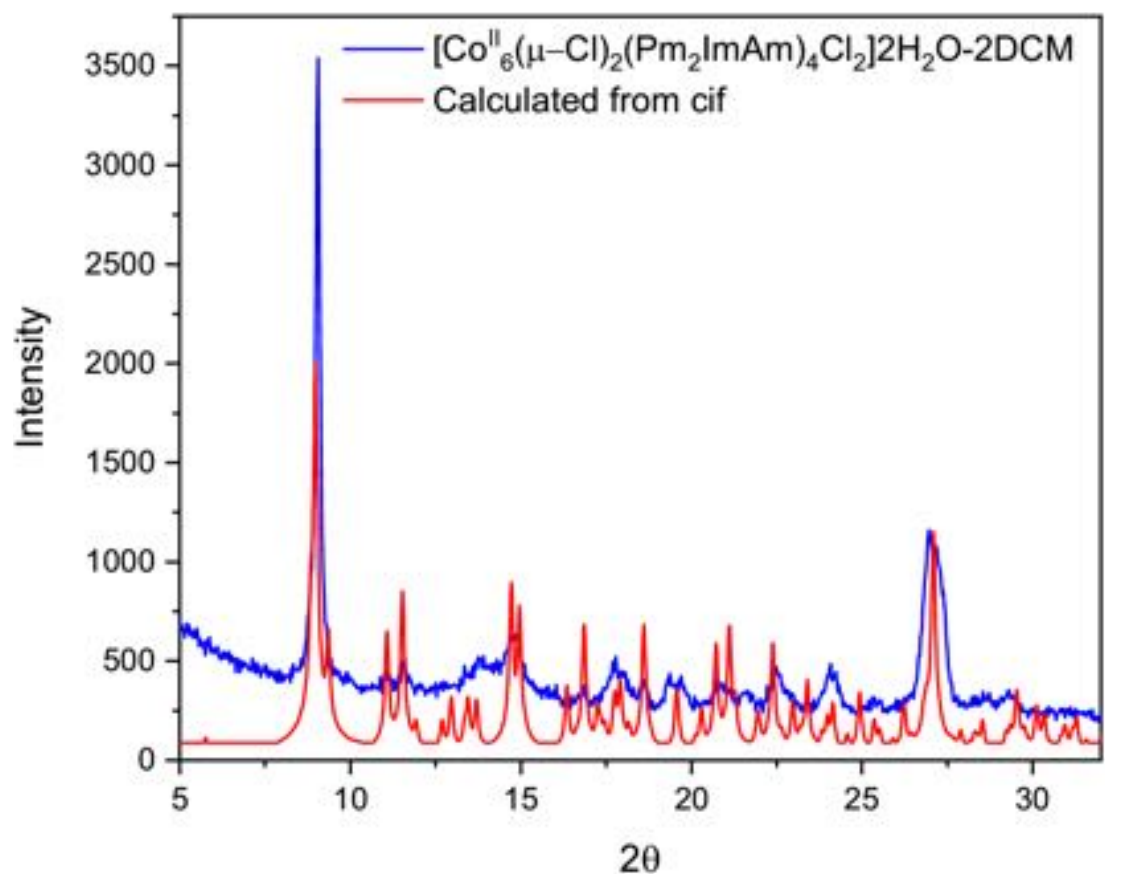

Figure S3. PXRD pattern overlay of the experimental microcrystalline [Co" $6{ }_{6}(\boldsymbol{\mu}$ $\left.\mathrm{Cl}_{2}\left(\mathrm{Pm}_{2} \mathrm{ImAm}\right)_{4} \mathrm{Cl}_{6}\right] \cdot \mathbf{2} \mathrm{CH}_{3} \mathrm{OH} \cdot \mathbf{2 C H}_{2} \mathrm{Cl}_{2}$ hexanuclear complex at room temperature with its calculated pattern from single crystal at $200 \mathrm{~K}$ using Mercury. ${ }^{3}$

X-ray crystallography. Data collection for single crystals of [Co"(Py2 $\left.\mathrm{ImAm})_{2}\right],\left[\mathrm{Co}_{3}{ }_{3}\left(\mathrm{Pm}_{2} \mathrm{ImAm}\right)_{2} \mathrm{Cl}_{4}\right] \cdot 5 \mathrm{H}_{2} \mathrm{O}$ and $\left[\mathrm{Co}_{6}{ }_{6}(\boldsymbol{\mu}-\mathrm{Cl})_{2}\left(\mathrm{Pm}_{2} \mathrm{ImAm}\right)_{4} \mathrm{Cl}_{6}\right] \cdot \mathbf{2} \mathrm{CH}_{3} \mathrm{OH} \cdot \mathbf{2} \mathrm{CH}_{2} \mathrm{Cl}_{2}$ (Table S1) were obtained on a Bruker KAPPA APEX-II CCD diffractometer (graphite monochromated Mo $K_{\alpha}$ radiation, $\lambda=0.71073 \AA$, $\omega$-scans with a $0.5^{\circ}$ step in $\omega$ ) at $200 \mathrm{~K}$. Absorption corrections were applied by using the semi-empirical method of the SADABS program ${ }^{4}$ for all samples. The structures were solved using SHELXT ${ }^{5}$ and refined by full-matrix leastsquares methods on $F^{2}$ with SHELXL-2015 ${ }^{6}$ in anisotropic approximation for all non-hydrogen atoms. The hydrogen atoms on pyridine or pyrimidine were constrained to ride on their parent atoms with $\mathrm{C}-\mathrm{H}=$ $0.95 \AA$ and $U_{\text {iso }}=1.2 U_{\text {eq }}(C)$, while imino $\mathrm{N}-\mathrm{H}$ hydrogen atoms were refined isotropically. SADI restrain was used to associate the imino $\mathrm{N}-\mathrm{H}$ distances with a 0.02 standard deviation in all the data sets. Some electron density contribution from solvents was removed using Squeeze protocol in the crystal structure of $\left[\mathrm{Co}_{3}{ }_{3}\left(\mathrm{Pm}_{2} \mathrm{ImAm}\right)_{2} \mathrm{Cl}_{4}\right] \cdot 5 \mathrm{H}_{2} \mathrm{O},{ }^{7}$ assuming that the electrons removed during squeezing were from water molecules. Powder X-ray diffraction (PXRD) was performed on a Rigaku Ultima IV diffractometer, with 
$\mathrm{Cu} K_{\alpha}$ monochromatic radiation $(\lambda=1.54056 \AA)$ and $\vartheta-2 \vartheta$ geometry. The simulated PXRD pattern was calculated using Mercury ${ }^{3}$ and was compared to the experimental PXRD of the bulk sample.

Table S1. Selected Crystallographic Data.

\begin{tabular}{|c|c|c|c|}
\hline Abbreviation & {$\left[\mathrm{Co}^{\prime \prime}\left(\mathrm{Py}_{2} \operatorname{ImAm}\right)_{2}\right]$} & $\begin{array}{l}{\left[\mathrm{Co}_{3}\left(\mathrm{Pm}_{2} \mathrm{ImAm}\right)_{2} \mathrm{Cl}_{4}\right]} \\
\cdot 5 \mathrm{H}_{2} \mathrm{O}\end{array}$ & $\begin{array}{l}{\left[\mathrm{Co}_{6}{ }_{6}(\mu-\mathrm{Cl})_{2}\left(\mathrm{Pm}_{2} \mathrm{ImAm}\right)_{4} \mathrm{Cl}_{6}\right]} \\
\cdot 2 \mathrm{CH}_{3} \mathrm{OH} \cdot 2 \mathrm{CH}_{2} \mathrm{Cl}_{2}\end{array}$ \\
\hline Empirical formula & $\mathrm{C}_{24} \mathrm{H}_{20} \mathrm{CoN}_{10}$ & $\mathrm{C}_{40} \mathrm{H}_{40} \mathrm{Cl}_{8} \mathrm{Co}_{6} \mathrm{~N}_{28} \mathrm{O}_{4}$ & $\mathrm{C}_{44} \mathrm{H}_{44} \mathrm{Cl}_{12} \mathrm{CO}_{6} \mathrm{~N}_{28} \mathrm{O}_{2}$ \\
\hline Formula weight & 507.43 & 1614.18 & 1776.05 \\
\hline Temperature (K) & 200 & 200 & 200 \\
\hline Crystal System & Monoclinic & Triclinic & Monoclinic \\
\hline Space group & $P 2_{1} / n$ & $P-1$ & $P 2_{1} / c$ \\
\hline$a(\AA)$ & $7.7384(9)$ & $7.2535(6)$ & $16.7152(9)$ \\
\hline$b(\AA)$ & $16.591(2)$ & $14.6590(12)$ & $13.0215(6)$ \\
\hline$c(\AA)$ & $8.8849(12)$ & $15.4268(12)$ & $16.2157(11)$ \\
\hline$\alpha\left(^{\circ}\right)$ & 90 & $90.5430(10)$ & 90 \\
\hline$B\left({ }^{\circ}\right)$ & $100.599(6)$ & $97.457(2)$ & $114.262(7)$ \\
\hline$\gamma\left({ }^{\circ}\right)$ & 90 & $90.4780(10)$ & 90 \\
\hline Volume $\left(\AA^{3}\right)$ & $1121.3(2)$ & $1626.3(2)$ & $3217.7(4)$ \\
\hline$z$ & 2 & 1 & 2 \\
\hline$\rho_{\text {calc }}(\mathrm{g} / \mathrm{mL})$ & 1.503 & 1.648 & 1.833 \\
\hline$\mu\left(\mathrm{mm}^{-1}\right)$ & 0.802 & 1.885 & 2.072 \\
\hline$F(000)$ & 522 & 806 & 1772.0 \\
\hline data collection range $\left({ }^{\circ}\right)$ & 4.91 to 66.092 & 5.326 to 55.994 & 4.114 to 56.998 \\
\hline Reflections collected & 31138 & 31758 & 52197 \\
\hline Independent reflections & 4080 & 7821 & 8022 \\
\hline Goof on $F^{2}$ & 1.056 & 1.027 & 1.074 \\
\hline$R_{1}[I \geq 2 \sigma(I)]$ & 0.0324 & 0.0363 & 0.1018 \\
\hline$w R_{2}$ all reflections & 0.0902 & 0.0873 & 0.2465 \\
\hline $\mathrm{H}$ atom treatment & Mixed & Mixed & Mixed \\
\hline
\end{tabular}


Table S2. List of relevant metal bond angles

\begin{tabular}{|c|c|c|c|c|c|}
\hline \multicolumn{2}{|c|}{$\left[\mathrm{Co}^{\prime \prime}\left(\mathrm{Py}_{2} \mathrm{ImAm}\right)_{2}\right]$} & \multicolumn{2}{|c|}{$\left[\mathrm{Co}_{3}{ }_{3}\left(\mathrm{Pm}_{2} \mathrm{ImAm}\right)_{2} \mathrm{Cl}_{4}\right] \cdot 5 \mathrm{H}_{2} \mathrm{O}$} & \multicolumn{2}{|c|}{$\left[\mathrm{Co}_{6}{ }_{6}(\mu-\mathrm{Cl})_{2}\left(\mathrm{Pm}_{2} \mathrm{ImAm}\right)_{4} \mathrm{Cl}_{8}\right] \cdot 2 \mathrm{CH}_{3} \mathrm{OH} \cdot 2 \mathrm{CH}_{2} \mathrm{Cl}_{2}$} \\
\hline Bond & Angle $\left({ }^{\circ}\right)$ & Bond & Angle $\left({ }^{\circ}\right)$ & Bond & Angle $\left(^{\circ}\right)$ \\
\hline N2-Co1-N4 & $88.99(5)$ & N3-Co1-N5 & $89.719(4)$ & N5-Co1-N3 & $89.1(3)$ \\
\hline N2-Co1-N4' & $91.01(5)$ & N3-Co1-N5' & $90.281(4)$ & N3-Co1-N12 & $90.1(3)$ \\
\hline N2-Co1-N2' & $180.00(6)$ & N3-Co1-N3' & $180.00(7)$ & N12-Co1-N10 & $89.8(3)$ \\
\hline \multirow[t]{19}{*}{ N4-Co1-N4' } & $180.00(6)$ & N5-Co1-N5' & $180.00(7)$ & N10-Co1-N5 & $90.6(3)$ \\
\hline & & N10-Co3-N12 & $89.656(4)$ & N5-Co1-N12 & $175.2(4)$ \\
\hline & & N10-Co3-N12' & $90.344(4)$ & N10-Co1-N3 & $175.0(4)$ \\
\hline & & N10-Co3-N10' & $180.00(7)$ & Cl4-Co1-N5 & $92.7(3)$ \\
\hline & & N12-Co3-N12' & $180.00(7)$ & $\mathrm{Cl} 4-\mathrm{Co} 1-\mathrm{N} 3$ & $93.4(3)$ \\
\hline & & N2-Co2-N4 & $76.970(3)$ & Cl4-Co1-N12 & $92.1(3)$ \\
\hline & & $\mathrm{N} 2-\mathrm{Co} 2-\mathrm{N} 6$ & $154.494(2)$ & Cl4-Co1-N10 & $91.7(3)$ \\
\hline & & N4-Co2-N6 & $77.849(5)$ & N2-Co2-N4 & $77.0(3)$ \\
\hline & & $\mathrm{Cl} 1-\mathrm{Co} 2-\mathrm{Cl} 2$ & $112.279(5)$ & N2-Co2-N6 & 149.1(3) \\
\hline & & $\mathrm{Cl} 1-\mathrm{Co} 2-\mathrm{N} 4$ & $132.8804(18)$ & N4-Co2-N6 & $77.1(3)$ \\
\hline & & $\mathrm{Cl} 2-\mathrm{Co} 2-\mathrm{N} 4$ & $114.841(4)$ & $\mathrm{Cl} 1-\mathrm{Co} 2-\mathrm{Cl} 2$ & $112.24(14)$ \\
\hline & & N9-Co4-N11 & $77.915(4)$ & $\mathrm{Cl} 1-\mathrm{Co} 2-\mathrm{N} 4$ & $103.9(2)$ \\
\hline & & N9-Co4-N13 & $154.4075(17)$ & $\mathrm{Cl} 2-\mathrm{Co} 2-\mathrm{N} 4$ & $143.7(2)$ \\
\hline & & N11-Co4-N13 & $76.747(5)$ & N9-Co3-N11 & $76.5(3)$ \\
\hline & & $\mathrm{Cl} 3-\mathrm{Co} 4-\mathrm{Cl} 4$ & $111.358(5)$ & N9-Co3-N13 & $151.5(3)$ \\
\hline & & Cl3-Co4-N11 & $118.083(4)$ & N11-Co3-N13 & $78.0(3)$ \\
\hline & & Cl4-Co4-N11 & $130.396(2)$ & $\mathrm{Cl} 3-\mathrm{Co} 3-\mathrm{Cl} 4$ & $106.89(10)$ \\
\hline & & & & Cl3-Co3-N11 & $109.6(2)$ \\
\hline & & & & $\mathrm{Cl} 3-\mathrm{Co} 3-\mathrm{Cl} 4$ & $106.89(10)$ \\
\hline
\end{tabular}

Magnetic Measurements. Magnetic susceptibility measurements were performed on a Quantum Design SQUID MPMS-XL magnetometer and PPMS-II susceptometer housed at the Centre de Recherche Paul Pascal at temperatures between 1.8 and $400 \mathrm{~K}$ and $d c$ magnetic fields ranging from -9 to $+9 \mathrm{~T}$. $A c$ magnetic susceptibility measurements were performed in an oscillating ac field of 1 to 6 Oe with frequencies between 1 and $10000 \mathrm{~Hz}$ and various $d c$ fields (including zero). The measurements were carried out on polycrystalline samples (16.16, 48.61 and $39.32 \mathrm{mg}$ for [Co"(Py $\mathbf{I m A m})_{2}$ ], $\left[\mathrm{Co}_{3}\left(\mathrm{Pm}_{2} \mathrm{ImAm}\right)_{2} \mathrm{Cl}_{4}\right]$, and $\left.\left[\mathrm{Co}_{6}{ }_{6}(\mu-\mathrm{Cl})_{2}\left(\mathrm{Pm}_{2} \mathrm{ImAm}\right)_{4} \mathrm{Cl}_{8}\right]\right)$ suspended in mineral oil (typically 10-20 $\mathrm{mg}$ ) and introduced in a sealed polyethylene bag $(3 \times 0.5 \times 0.02 \mathrm{~cm}$; typically $24-32 \mathrm{mg})$. Prior to the experiments, the field-dependent magnetization was measured at $100 \mathrm{~K}$ on each sample in order to detect the presence of any bulk ferromagnetic impurities. In fact, paramagnetic or diamagnetic materials should exhibit a perfectly linear dependence of the magnetization that extrapolates to zero at zero $d c$ field; the samples appeared to be free of any ferromagnetic impurities. The magnetic susceptibilities were corrected for the sample holder, the oil and the intrinsic diamagnetic contributions. 


\section{Crystal Structure Figures and Tables}

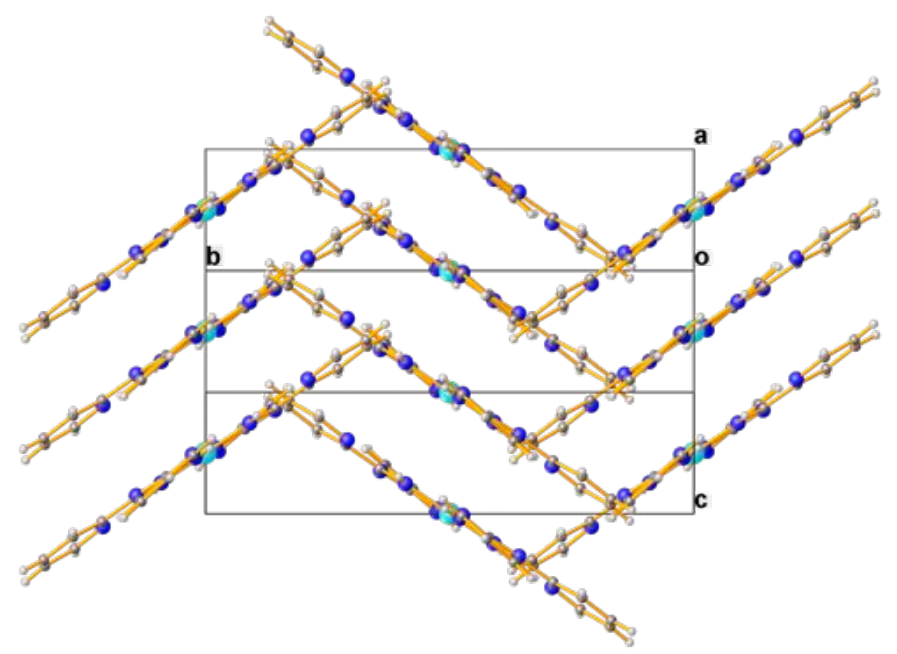

Figure S4. Crystal packing of [Co"(Py2lmAm) 2 ] at $200 \mathrm{~K}$ viewed along the 201 plane.
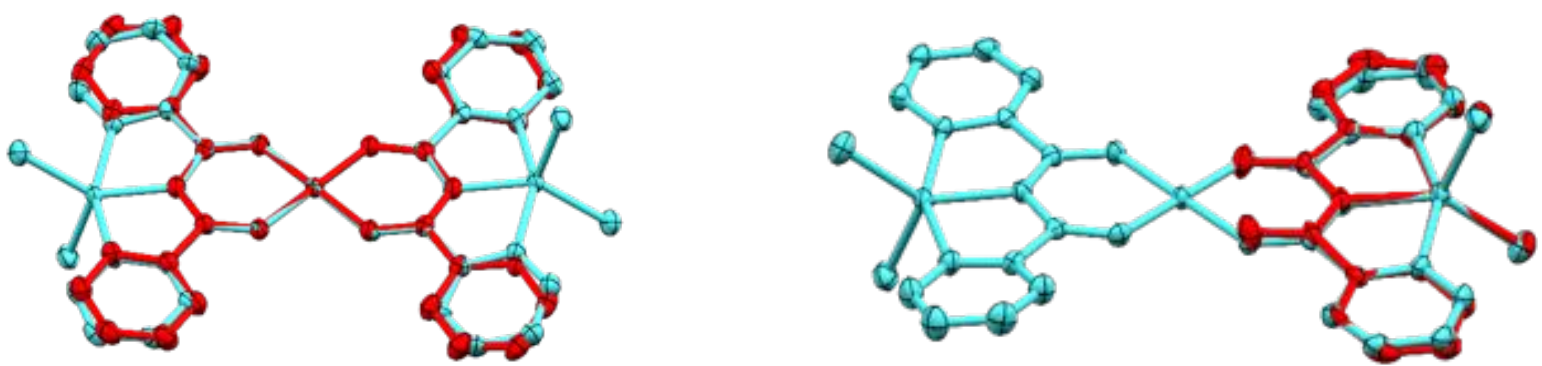

Figure S5. Structural overlay at $200 \mathrm{~K}$ of (left) mononuclear [Co"(Py2 ImAm) $)_{2}$ (red) with trinuclear [Co" ${ }_{3}\left(\mathrm{Pm}_{2} \mathrm{ImAm}\right)_{2} \mathrm{Cl}_{4}$ ] (blue) and (right) mononuclear [Co"(Py $\left.\left.\mathbf{I m A m}\right) \mathrm{Cl}_{2}\right]$ (red) with [Co" $\left.{ }_{3}\left(\mathrm{Pm}_{2} \mathrm{ImAm}\right)_{2} \mathrm{Cl}_{4}\right]$ (blue). Hydrogen atoms have been omitted for clarity. 

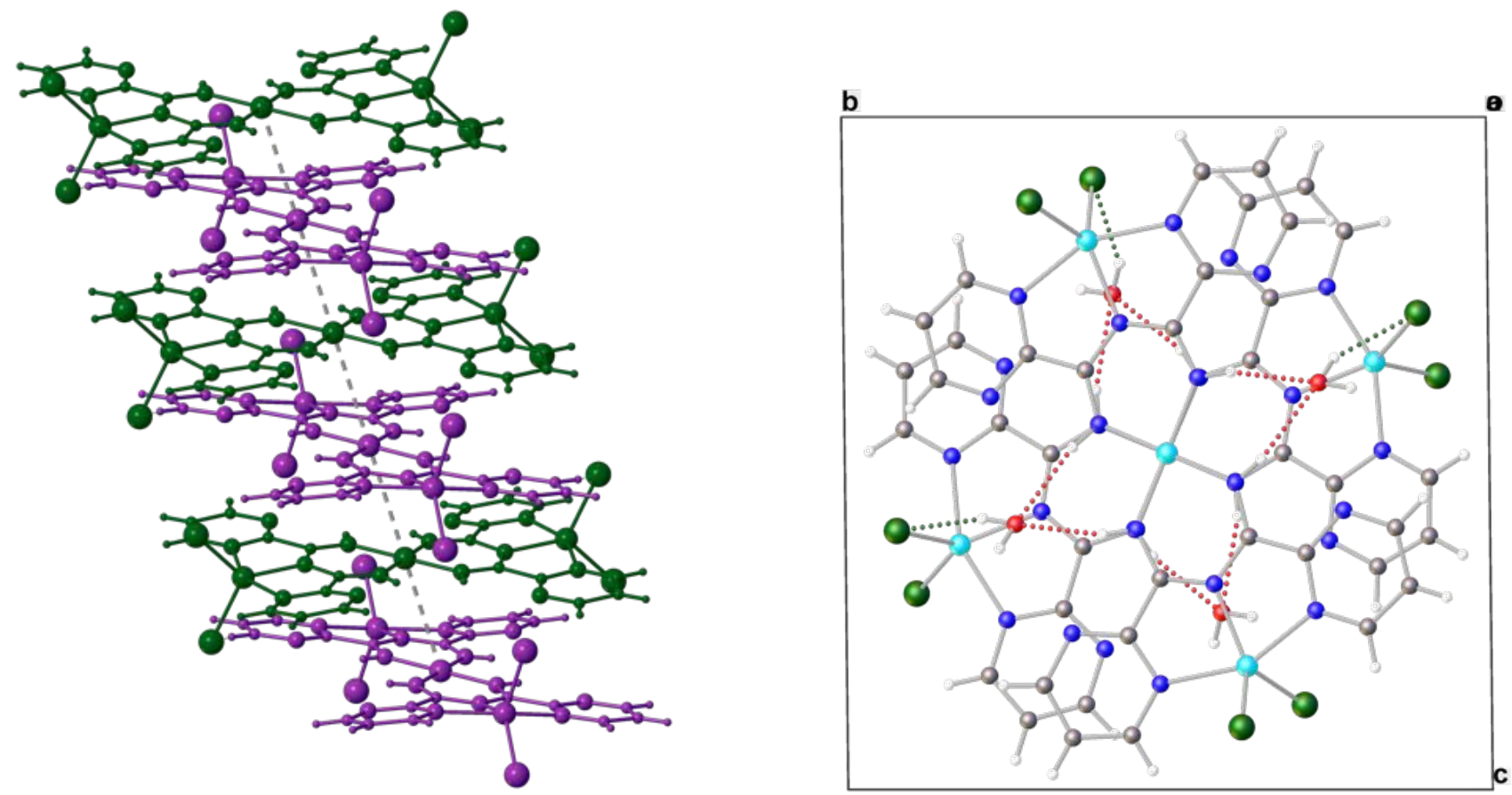

Figure S6. View of a single stack in $\left[\mathrm{Co}_{3}{ }_{3}\left(\mathrm{Pm}_{2} \mathrm{ImAm}\right)_{2} \mathrm{Cl}_{4}\right] \cdot 5 \mathrm{H}_{2} \mathrm{O}$ at $200 \mathrm{~K}$ with independent crystallographic molecules in different color. A gray dashed line was drawn to indicate short Co-Co distances (left). Top view of a single stack along the (100) plane in $\left[\mathrm{Co}_{3}{ }_{3}\left(\mathrm{Pm}_{2} \mathrm{ImAm}\right)_{2} \mathrm{Cl}_{4}\right] \cdot \mathbf{5 H}_{\mathbf{2}} \mathrm{O}$ (right). N$\mathrm{H} \cdots \mathrm{O}$ hydrogen bonds are denoted as red dashed lines, and $\mathrm{O}-\mathrm{H} \cdots \mathrm{Cl}$ as green dashed lines.
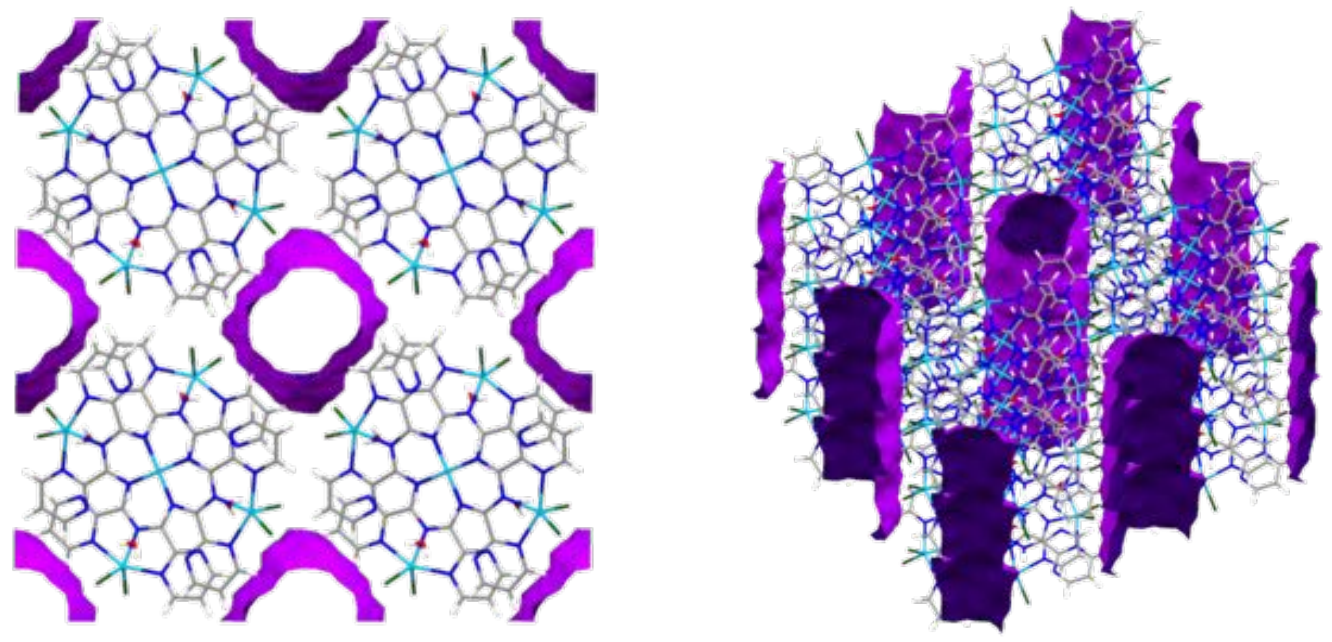

Figure S7. Top view (left) and side view (right) of solvent channels in $\left[\mathrm{Co}_{3}{ }_{3}\left(\mathrm{Pm}_{2} \mathrm{ImAm}\right)_{2} \mathrm{Cl}_{4}\right] \cdot 5 \mathrm{H}_{2} \mathrm{O}$ at $200 \mathrm{~K}$. 
(a)

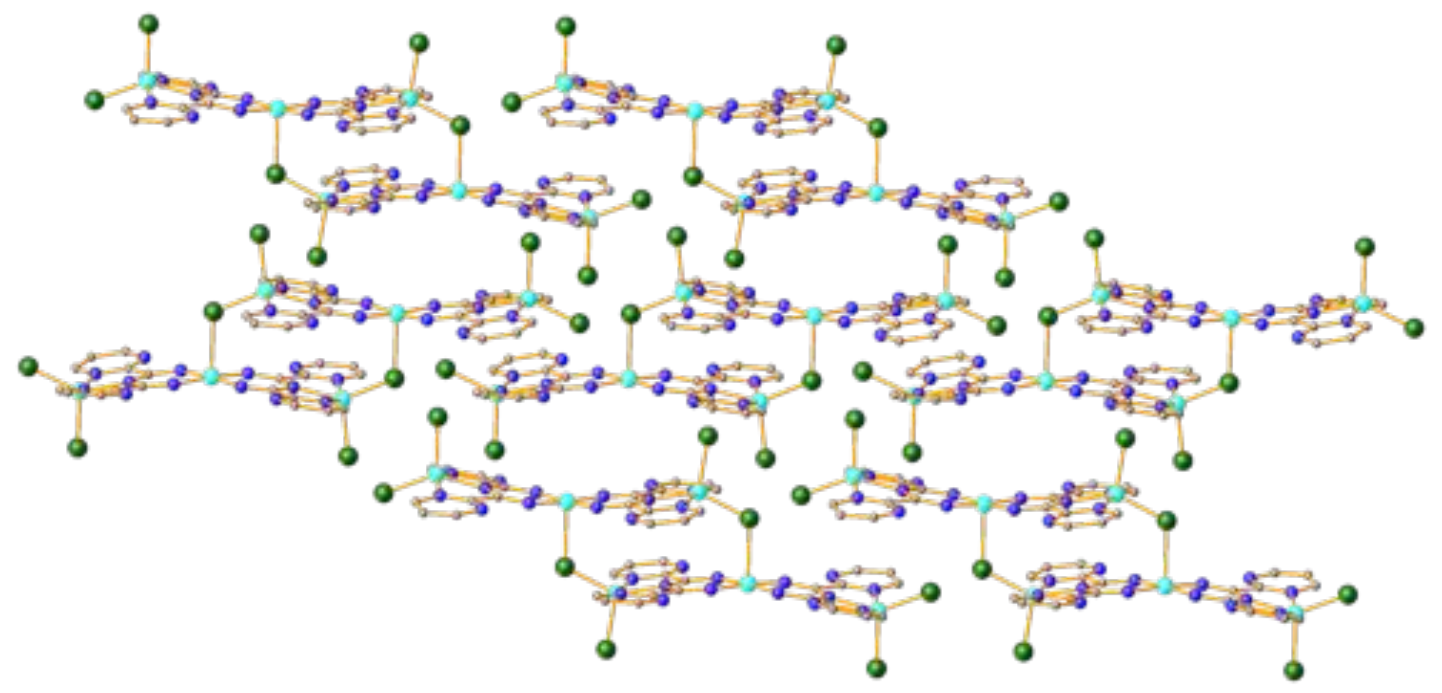

(b)

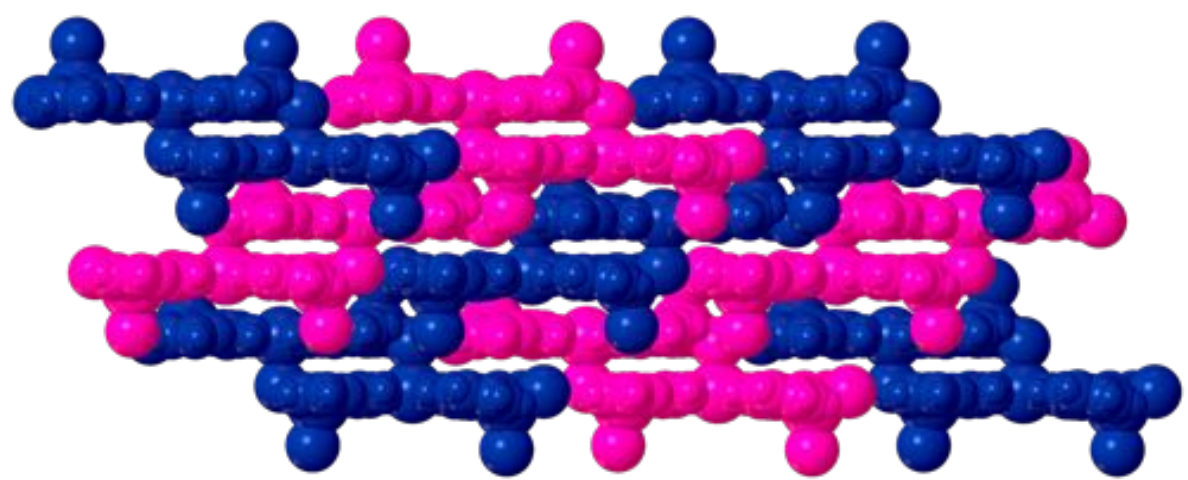

Figure 58. Two views of the brick-like packing of $\left[\mathrm{Co}_{6}{ }_{6}(\mu-\mathrm{Cl})_{2}\left(\mathrm{Pm}_{2} \mathrm{ImAm}\right)_{4} \mathrm{Cl}_{8}\right] \cdot \mathbf{2} \mathrm{H}_{2} \mathbf{O} \cdot \mathbf{2} \mathrm{CH}_{2} \mathrm{Cl}_{2}$ at $200 \mathrm{~K}$. In (b), individual molecules are differentiated by colour coding in blue and pink.

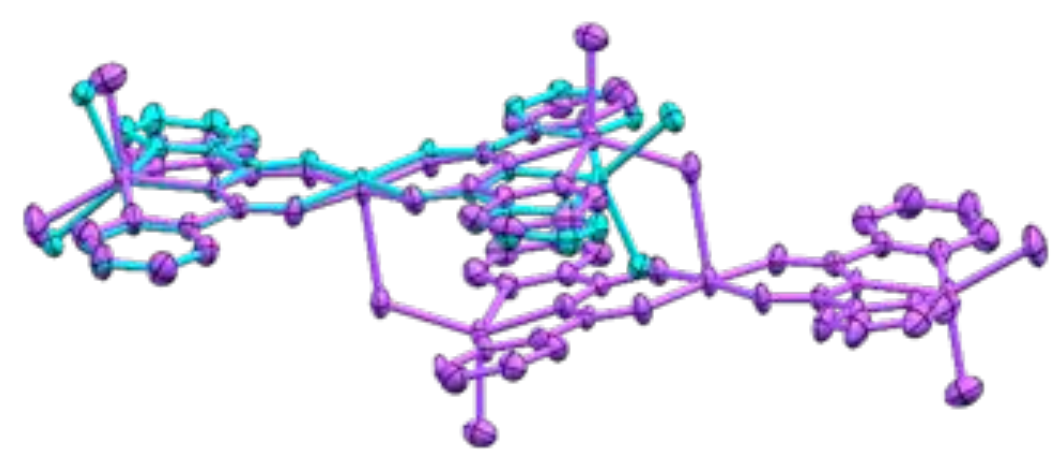

Figure 59. Structural overlay at $200 \mathrm{~K}$ of trinuclear [ $\left.\mathrm{Co}_{3}{ }_{3}\left(\mathrm{Pm}_{2} \mathrm{ImAm}\right)_{2} \mathrm{Cl}_{4}\right]$ (blue) with hexanuclear [ $\mathrm{Co}_{6}{ }_{6}(\mu-$ $\left.\mathrm{Cl}_{2}\left(\mathrm{Pm}_{2} / \mathrm{mAm}\right)_{4} \mathrm{Cl}_{8}\right]$ (violet). Hydrogen atoms have been omitted for clarity. 
Table S3. Hydrogen bonds in the structures discussed.

\begin{tabular}{|c|c|c|c|c|c|}
\hline$D-\mathrm{H} \cdots A$ & Type & $D-\mathrm{H}$ & $\mathrm{H} \cdots A$ & $D \cdots A$ & $<(\mathrm{DHA})$ \\
\hline \multicolumn{6}{|l|}{ [Co"(Py. ImAm) $\left.)_{2}\right]$} \\
\hline $\mathrm{N} 2-\mathrm{H} 2 \mathrm{~A} \cdots \mathrm{N} 1$ & Intra & $0.86(2)$ & $2.17(2)$ & $2.694(2)$ & $119.1(13)$ \\
\hline 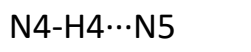 & Intra & $0.84(2)$ & $2.20(2)$ & $2.72(1)$ & $118.9(14)$ \\
\hline \multicolumn{6}{|c|}{$\left[\mathrm{Co}_{3}\left(\mathrm{Pm}_{2} \mathrm{ImAm}\right)_{2} \mathrm{Cl}_{4}\right] \cdot 5 \mathrm{H}_{2} \mathrm{O}$} \\
\hline 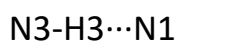 & Intra & $0.81(2)$ & $2.38(2)$ & $2.800(3)$ & $113(2)$ \\
\hline 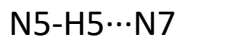 & Intra & $0.81(2)$ & $2.39(2)$ & $2.801(3)$ & $113(2)$ \\
\hline $\mathrm{N} 10-\mathrm{H} 10 \cdots \mathrm{N} 8$ & Intra & $0.82(2)$ & $2.36(3)$ & $2.779(3)$ & $113(2)$ \\
\hline $\mathrm{N} 12-\mathrm{H} 12 \cdots \mathrm{N} 14$ & Intra & $0.81(3)$ & $2.43(3)$ & $2.821(3)$ & $111(2)$ \\
\hline $\mathrm{O} 1-\mathrm{H} 1 \mathrm{~A} \cdots \mathrm{Cl} 1^{\mathrm{i}}$ & Inter & $0.85(3)$ & $2.55(4)$ & $3.338(2)$ & $155(4)$ \\
\hline $\mathrm{O} 1-\mathrm{H} 1 \mathrm{~A} \cdots \mathrm{N} 8^{\mathrm{i}}$ & Inter & $0.85(3)$ & $2.59(4)$ & $3.010(3)$ & $112(3)$ \\
\hline $\mathrm{O} 1-\mathrm{H} 1 \mathrm{~B} \cdots \mathrm{Cl} 2^{\mathrm{ii}}$ & Inter & $0.84(3)$ & $2.49(3)$ & $3.288(2)$ & $161(4)$ \\
\hline $\mathrm{O} 2-\mathrm{H} 2 \mathrm{~A} \cdots \mathrm{Cl} 44^{\mathrm{ii}}$ & Inter & $0.85(3)$ & $2.47(3)$ & $3.258(2)$ & $154(4)$ \\
\hline $\mathrm{O} 2-\mathrm{H} 2 \mathrm{~A} \cdots \mathrm{N} 7^{\mathrm{ii}}$ & Inter & $0.85(3)$ & $2.60(4)$ & 3.040(3) & $113(3)$ \\
\hline $\mathrm{O} 2-\mathrm{H} 2 \mathrm{~B} \cdots \mathrm{Cl}^{\mathrm{i}}$ & Inter & $0.82(3)$ & $2.77(4)$ & $3.412(2)$ & $137(4)$ \\
\hline $\mathrm{O} 2-\mathrm{H} 2 \mathrm{~B} \cdots \mathrm{N} 1^{\mathrm{iii}}$ & Inter & $0.82(3)$ & $2.50(4)$ & $3.062(3)$ & $127(4)$ \\
\hline $\mathrm{N} 3-\mathrm{H} 3 \cdots \mathrm{O} 2^{\mathrm{iii}}$ & Inter & $0.81(2)$ & $2.23(2)$ & $3.019(3)$ & $164(2)$ \\
\hline $\mathrm{N} 5-\mathrm{H} 5 \cdots \mathrm{O} 2^{\mathrm{iv}}$ & Inter & $0.81(2)$ & $2.21(2)$ & $2.994(3)$ & $164(2)$ \\
\hline $\mathrm{N} 10-\mathrm{H} 10 \cdots \mathrm{O} 1^{\mathrm{i}}$ & Inter & $0.82(2)$ & $2.19(2)$ & $2.991(3)$ & $165(3)$ \\
\hline $\mathrm{N} 12-\mathrm{H} 12 \cdots \mathrm{O} 1^{\mathrm{iii}}$ & Inter & $0.81(3)$ & $2.19(3)$ & $2.987(3)$ & $166(2)$ \\
\hline $\mathrm{C} 1-\mathrm{H} 1 \cdots \mathrm{Cl} 3^{\mathrm{iii}}$ & Inter & 0.95 & 2.78 & $3.606(3)$ & 146 \\
\hline $\mathrm{C} 2-\mathrm{H} 2 \cdots \mathrm{Cl} 1^{v}$ & Inter & 0.95 & 2.72 & $3.663(3)$ & 172 \\
\hline $\mathrm{C} 11-\mathrm{H} 11 \cdots \mathrm{Cl} 2^{\mathrm{vi}}$ & Inter & 0.95 & 2.82 & $3.615(3)$ & 142 \\
\hline $\mathrm{C} 19-\mathrm{H} 19 \cdots \mathrm{Cl}^{\mathrm{vii}}$ & Inter & 0.95 & 2.70 & $3.545(3)$ & 148 \\
\hline
\end{tabular}

$\left[\mathrm{CO}_{6}{ }_{6}(\mu-\mathrm{Cl})_{2}\left(\mathrm{Pm}_{2} \mathrm{ImAm}\right)_{4} \mathrm{Cl}_{6}\right] \cdot 2 \mathrm{CH}_{3} \mathrm{OH} \cdot 2 \mathrm{CH}_{2} \mathrm{Cl}_{2}$

\begin{tabular}{llllll}
\hline $\mathrm{N} 3-\mathrm{H} 3 \cdots \mathrm{N} 1$ & Intra & $0.84(4)$ & $2.30(7)$ & $2.760(12)$ & $115(6)$ \\
$\mathrm{N} 5-\mathrm{H} 5 \cdots \mathrm{N} 7$ & Intra & $0.84(6)$ & $2.30(7)$ & $2.782(11)$ & $117(7)$ \\
$\mathrm{N} 10-\mathrm{H} 10 \cdots \mathrm{N} 8$ & Intra & $0.84(5)$ & $2.25(9)$ & $2.805(11)$ & $124(8)$ \\
$\mathrm{N} 12-\mathrm{H} 12 \cdots \mathrm{N} 14$ & Intra & $0.85(6)$ & $2.29(7)$ & $2.741(10)$ & $114(7)$ \\
$\mathrm{N} 5-\mathrm{H} 5 \cdots \mathrm{O} 1^{i}$ & Inter & $0.84(6)$ & $2.27(7)$ & $3.013(12)$ & $149(7)$ \\
$\mathrm{N} 10-\mathrm{H} 10 \cdots \mathrm{O} 1^{i}$ & Inter & $0.84(5)$ & $2.32(7)$ & $3.047(12)$ & $145(10)$ \\
$\mathrm{O} 1-\mathrm{H} 1 \mathrm{~A} \cdots \mathrm{Cl}^{\text {viii }}$ & Inter & 0.84 & 2.39 & $3.220(9)$ & 170 \\
$\mathrm{C} 3-\mathrm{H} 3 \mathrm{~A} \cdots \mathrm{Cl} 4^{\text {iv }}$ & Inter & 0.95 & 2.61 & $3.407(13)$ & 142 \\
$\mathrm{C} 8-\mathrm{H} 8 \cdots \mathrm{Cl} 3^{\text {ix }}$ & Inter & 0.95 & 2.79 & $3.603(12)$ & 144 \\
$\mathrm{C} 10-\mathrm{H} 10 \mathrm{~A} \cdots \mathrm{Cl} 1^{x}$ & Inter & 0.95 & 2.70 & $3.532(11)$ & 147 \\
$\mathrm{C} 13-\mathrm{H} 13 \cdots \mathrm{Cl} 2^{i i}$ & Inter & 0.95 & 2.55 & $3.391(11)$ & 147 \\
$\mathrm{C} 20-\mathrm{H} 20 \cdots \mathrm{Cl} 3^{\mathrm{xi}}$ & Inter & 0.95 & 2.69 & $3.476(9)$ & 140
\end{tabular}

Symmetry codes: ' $x, y, z$; ii $1+x, y, z$; iii $1-x, 1-y, 1-z$; ${ }^{\text {iv }}-1+x, y, z$; ${ }^{v} 1-x,-y, 1$ $-z ;{ }^{\text {vi }}-x, 1-y, 1-z$; vii $1-x, 1-y,-z ;{ }^{\text {viii }}-x,-1 / 2+y, 1 / 2-z ;{ }^{i x}-1+x, 3 / 2-y,-1 / 2+z ;{ }^{x} x$, $3 / 2-y,-1 / 2+z ; x$ 
Table S4. Cobalt-Nitrogen distances in [Co"(Py $\left.\mathbf{I m A m})_{2}\right]$ at $200 \mathrm{~K}$.

\begin{tabular}{lll}
\hline Connectivity & Type & Distance $(\AA ̊)$ \\
\hline N2 to Co1 & Square planar & $1.8471(10)$ \\
N4 to Co1 & Square planar & $1.8563(11)$ \\
\hline
\end{tabular}

Table S5. Cobalt-Nitrogen distances in $\left[\mathrm{Co}_{3}{ }_{3}\left(\mathrm{Pm}_{2} \mathrm{ImAm}\right)_{2} \mathrm{Cl}_{4}\right] \cdot 5 \mathrm{H}_{2} \mathrm{O}$ at $200 \mathrm{~K}$.

\begin{tabular}{lll|lll}
\hline Molecule A & & & Molecule B & & \\
\hline Connectivity & Type & Distance $(\AA)$ & Connectivity & Type & Distance $(\AA)$ \\
\hline N5 to Co1 & Square planar & $1.87911(13)$ & N10 to Co3 & Square planar & $1.86476(13)$ \\
N3 to Co1 & Square planar & $1.87931(11)$ & N12 to Co3 & Square planar & $1.88707(11)$ \\
N4 to Co2 & Terpy central N & $2.02538(14)$ & N11 to Co4 & Terpy central N & $2.03279(14)$ \\
N6 to Co2 & Terpy & $2.14924(15)$ & N13 to Co4 & Terpy & $2.14839(15)$ \\
N2 to Co2 & Terpy & $2.14610(12)$ & N9 to Co4 & Terpy & $2.14686(12)$ \\
Cl1 to Co2 & Terpy & $2.28003(12)$ & Cl3 to Co4 & Terpy & $2.28273(12)$ \\
Cl2 to Co2 & Terpy & $2.27888(13)$ & Cl4 to Co4 & Terpy & $2.27468(15)$ \\
\hline
\end{tabular}

*There are two crystallographic independent molecules

Table S6. Cobalt-Nitrogen distances in $\left[\mathrm{Co}_{6}{ }_{6}(\mu-\mathrm{Cl})_{2}\left(\mathrm{Pm}_{2} \mathrm{ImAm}\right)_{4} \mathrm{Cl}_{6}\right] \cdot 2 \mathrm{CH}_{3} \mathrm{OH} \cdot 2 \mathrm{CH}_{2} \mathrm{Cl}_{2}$ at $200 \mathrm{~K}$.

\begin{tabular}{lll}
\hline Connectivity & Type & Distance $(\AA ̊)$ \\
\hline N3 to Co1 & Square pyramidal & $1.918(7)$ \\
N5 to Co1 & Square pyramidal & $1.888(7)$ \\
N10 to Co1 & Square pyramidal & $1.890(7)$ \\
N12 to Co1 & Square pyramidal & $1.894(7)$ \\
Cl4 to Co1 & Square pyramidal & $2.628(3)$ \\
N4 to Co2 & Terpy central N & $2.029(6)$ \\
N2 to Co2 & Terpy & $2.131(9)$ \\
N6 to Co2 & Terpy & $2.109(9)$ \\
Cl2 to Co2 & Terpy & $2.263(3)$ \\
Cl1 to Co2 & Terpy & $2.298(3)$ \\
N11 to Co3 & Terpy central N & $2.014(7)$ \\
N9 to Co3 & Terpy & $2.156(7)$ \\
N13 to Co3 & Terpy & $2.140(8)$ \\
Cl3 to Co3 & Terpy & $2.295(3)$ \\
Cl4 to Co3 & Terpy & $2.286(2)$ \\
\hline
\end{tabular}


Table S7. List of intra stack cobalt to cobalt distances within $\left[\mathrm{Co}_{3}{ }_{3}\left(\mathrm{Pm}_{2} \mathrm{ImAm}\right)_{2} \mathrm{Cl}_{4}\right] \cdot 5 \mathrm{H}_{2} \mathrm{O}$ at $200 \mathrm{~K}$.

\begin{tabular}{ll}
\hline Connectivity & Distance $(\AA)$ \\
\hline Co1-Co3 & $3.6268(3)$ \\
Co1-Co2 & $5.2932(4)$ \\
Co1-Co4 & $5.7287(4)$ \\
Co1-Co4 & $7.0448(4)$ \\
Co1-Co1 & $7.2535(6)$ \\
Co1-Co2 & $7.9347(5)$ \\
Co1-Co2 & $9.9148(6)$ \\
Co2-Co3 & $5.6865(3)$ \\
Co2-Co3 & $7.0716(4)$ \\
Co2-Co4 & $7.2028(5)$ \\
Co2-Co2 & $7.2535(6)$ \\
Co2-Co4 & $8.3024(5)$ \\
Co3-Co4 & $5.2981(4)$ \\
Co3-Co3 & $7.2535(6)$ \\
Co4-Co4 & $7.2535(6)$ \\
\hline
\end{tabular}

Table S8. List of inter stack cobalt to cobalt distances within $\left[\mathrm{Co}_{3}{ }_{3}\left(\mathrm{Pm}_{2} \mathrm{ImAm}\right)_{2} \mathrm{Cl}_{4}\right] \cdot 5 \mathrm{H}_{2} \mathrm{O}$ at $200 \mathrm{~K}$.

\begin{tabular}{ll}
\hline Connectivity & Distance (Å) \\
\hline Co2-Co2 & $7.0704(4)$ \\
Co2-Co2 & $8.3087(4)$ \\
Co2-Co4 & $8.6895(6)$ \\
Co2-Co4 & $9.0765(6)$ \\
Co4-Co4 & $7.2300(4)$ \\
Co4-Co4 & $7.8947(4)$ \\
\hline
\end{tabular}

Table S9. List of intramolecular cobalt to cobalt distances at $200 \mathrm{~K}$ within $\left[\mathrm{Co}_{6}{ }_{6}\left(\mu-\mathrm{Cl}_{2}\left(\mathrm{Pm}_{2} \mathrm{ImAm}\right)_{4} \mathrm{Cl}_{6}\right]\right.$ $\cdot 2 \mathrm{CH}_{3} \mathrm{OH} \cdot 2 \mathrm{CH}_{2} \mathrm{Cl}_{2}$.

\begin{tabular}{ll}
\hline Connectivity & Distance $(\AA)$ \\
\hline Co1-Co3 & $4.1545(17)$ \\
Co1-Co3 & $5.2881(16)$ \\
Co1-Co2 & $5.2969(17)$ \\
Co1-Co1 & $7.0448(4)$ \\
Co2-Co3 & $7.897(2)$ \\
Co2-Co3 & $8.5607(16)$ \\
Co3-Co3 & $5.299(2)$ \\
\hline
\end{tabular}


Table S10. List of intermolecular cobalt to cobalt distances at $200 \mathrm{~K}$ within $\left[\mathrm{Co}_{6}{ }_{6}\left(\mu-\mathrm{Cl}_{2}\left(\mathrm{Pm}_{2} \mathrm{ImAm}\right)_{4} \mathrm{Cl}_{6}\right]\right.$ $\cdot 2 \mathrm{CH}_{3} \mathrm{OH} \cdot 2 \mathrm{CH}_{2} \mathrm{Cl}_{2}$.

\begin{tabular}{ll}
\hline Connectivity & Distance $(\AA ̊)$ \\
\hline Co1-Co2 & $6.628(2)$ \\
Co1-Co2 & $7.2427(18)$ \\
Co1-Co2 & $8.6454(18)$ \\
Co1-Co1 & $8.8644(12)$ \\
Co1-Co2 & $9.2029(18)$ \\
Co1-Co3 & $9.2543(17)$ \\
Co2-Co3 & $6.2523(15)$ \\
Co2-Co2 & $6.315(3)$ \\
Co2-Co3 & $6.968(2)$ \\
Co2-Co2 & $8.210(2)$ \\
Co2-Co2 & $8.3211(8)$ \\
Co2-Co2 & $9.414(3)$ \\
Co3-Co3 & $8.4163(8)$ \\
Co3-Co3 & $9.321(2)$ \\
\hline
\end{tabular}




\section{Shape Analysis}

Table S11. Shape analysis results for pentacoordinate environment in $\left[\mathrm{Co}_{3}{ }_{3}\left(\mathrm{Pm}_{2} \mathrm{ImAm}\right)_{2} \mathrm{Cl}_{4}\right] \cdot 5 \mathrm{H}_{2} \mathrm{O}$ at $200 \mathrm{~K}$.

\begin{tabular}{lllllll}
\hline Molecule & Metal Centre & PP-5 & vOC-5 & TBPY-5 & SPY-5 & JTBPY-5 \\
\hline Molecule A & Co2 & 31.316 & 5.310 & 2.487 & 2.950 & 6.037 \\
Molecule B & Co4 & 31.026 & 5.789 & 2.425 & 3.257 & 6.006 \\
\hline
\end{tabular}

PP-5: $D_{5 h}$, Pentagon; vOC-5: $C_{4 v}$, Vacant octahedron; TBPY-5: $D_{3 h}$, Trigonal bipyramid; SPY-5: $C_{4 v}$, Spherical square pyramid; JPPY-6: $C_{5 v}$, Johnson trigonal bipyramid J12
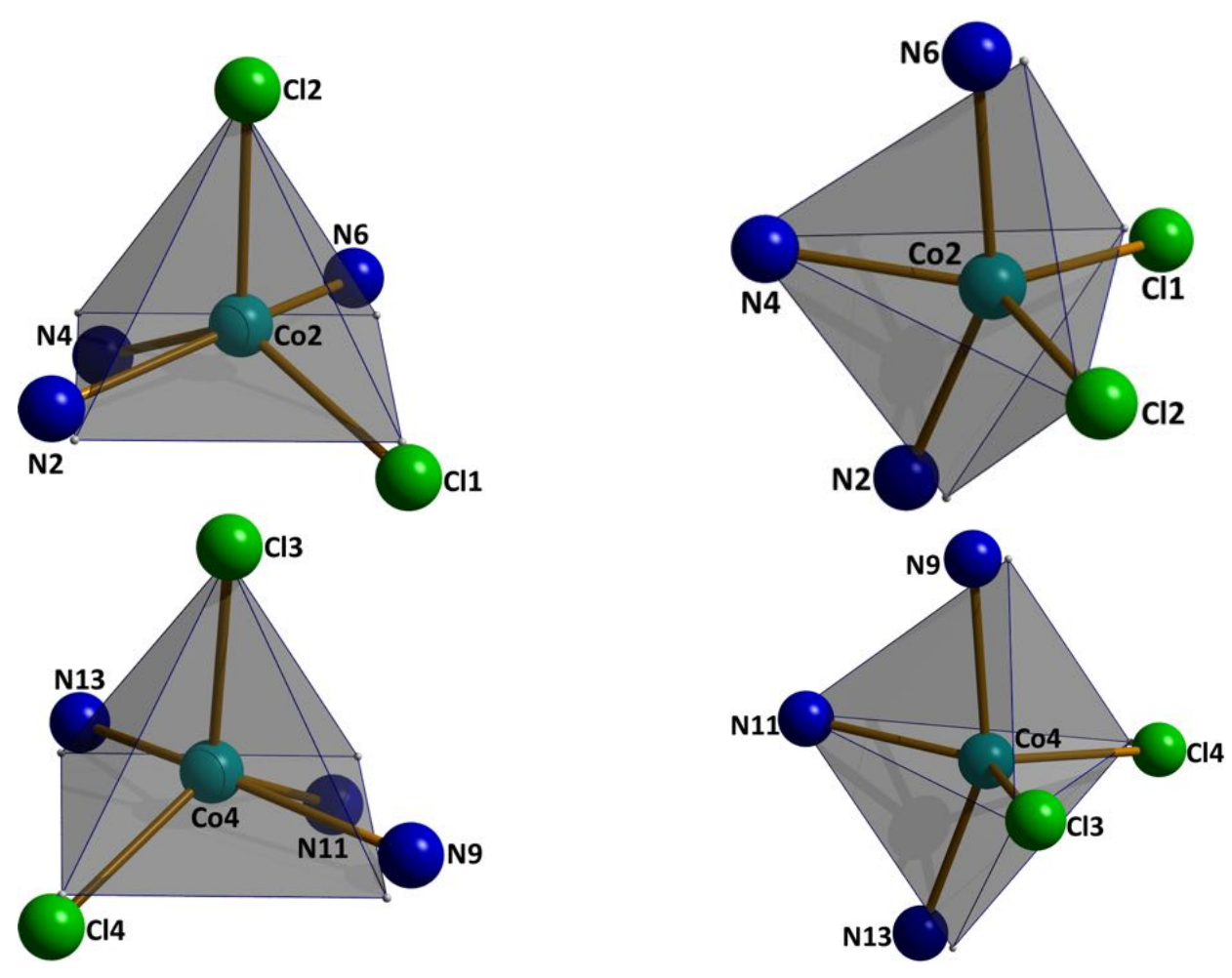

Figure S10. Deviation from ideal square pyramidal (left) or trigonal bipyramidal (right) within molecule A (top) and B (bottom) in [ $\left.\mathrm{Co}_{3}{ }_{3}\left(\mathrm{Pm}_{2} \mathrm{ImAm}\right)_{2} \mathrm{Cl}_{4}\right] \cdot 5 \mathrm{H}_{2} \mathrm{O}$ at $200 \mathrm{~K}$. Cobalt atoms are depicted light blue and located in the center of an ideal square pyramid or trigonal bipyramid. 
Table S12. Shape analysis results for pentacoordinate environment in [Co" 6 ( $\boldsymbol{\mu}$ $\left.\mathrm{Cl})_{2}\left(\mathrm{Pm}_{2} \mathrm{ImAm}\right)_{4} \mathrm{Cl}_{6}\right] \cdot 2 \mathrm{CH}_{3} \mathrm{OH} \cdot 2 \mathrm{CH}_{2} \mathrm{Cl}_{2}$ at $200 \mathrm{~K}$.

\begin{tabular}{llllll}
\hline Metal Centre & PP-5 & vOC-5 & TBPY-5 & SPY-5 & JTBPY-5 \\
\hline Co1 & 34.254 & 2.195 & 6.235 & 1.076 & 9.774 \\
Co2 & 32.738 & 3.720 & 4.482 & 1.375 & 8.197 \\
Co3 & 31.124 & 3.752 & 4.127 & 1.647 & 7.584 \\
\hline
\end{tabular}

PP-5: $D_{5 h}$, Pentagon; vOC-5: $C_{4 v}$, Vacant octahedron; TBPY-5: $D_{3 h}$, Trigonal bipyramid; SPY-5: $C_{4 v}$, Spherical square pyramid; JPPY-6: $C_{5 v}$, Johnson trigonal bipyramid $\mathrm{J} 12$
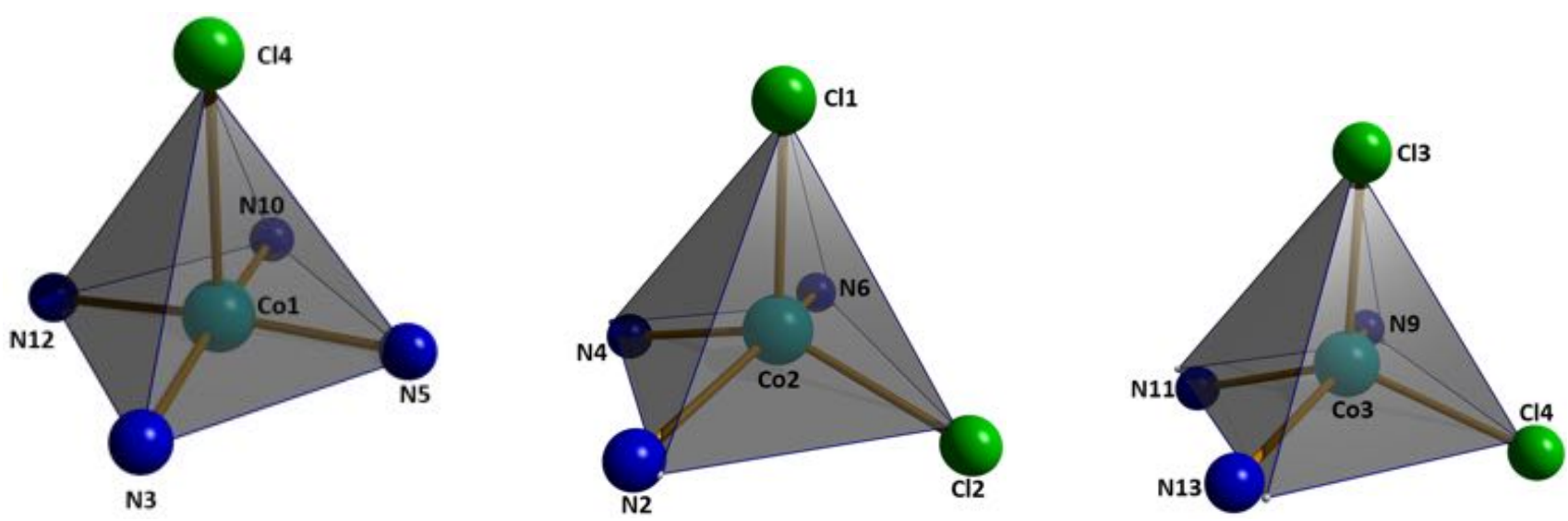

Figure S11. Deviation from ideal square pyramidal geometry in [Co"6 6 ( $\mu$ $\left.\mathrm{Cl}_{2}\left(\mathrm{Pm}_{2} \mathrm{ImAm}\right)_{4} \mathrm{Cl}_{6}\right] \cdot 2 \mathrm{CH}_{3} \mathrm{OH} \cdot 2 \mathrm{CH}_{2} \mathrm{Cl}_{2}$ at $200 \mathrm{~K}$. Cobalt atoms are depicted light blue and located in the center of an ideal square pyramid.

\section{Thermogravimetric Analysis}

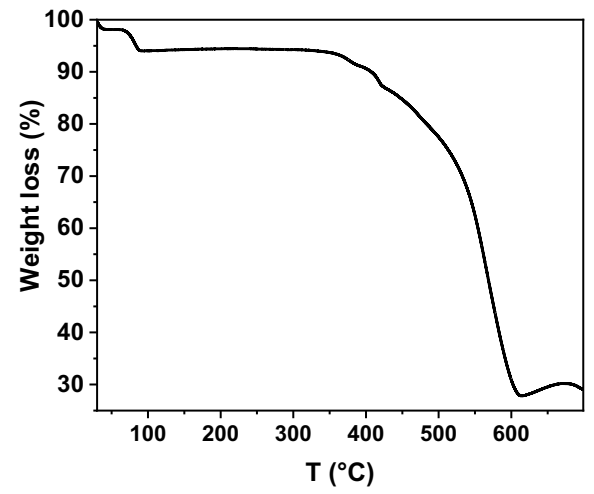

Figure S12. Thermogravimetric analysis of $\left[\mathrm{Co}_{3}{ }_{3}\left(\mathrm{Pm}_{2} \mid \mathrm{mAm}\right)_{2} \mathrm{Cl}_{4}\right] \cdot 5 \mathrm{H}_{2} \mathrm{O}$ revealing a $6 \%$ weight loss below $100^{\circ} \mathrm{C}$, which corresponds to the loss of three water molecules and is consistent with the SCXRD in which two of the five water molecules are bound by hydrogen bonds to three $\left[\mathrm{Co}^{\prime \prime}{ }_{3}\left(\mathrm{Pm}_{2} \mathbf{I m A m}\right)_{2} \mathrm{Cl}_{4}\right]$ complexes. 


\section{Additional Magnetic Measurements}

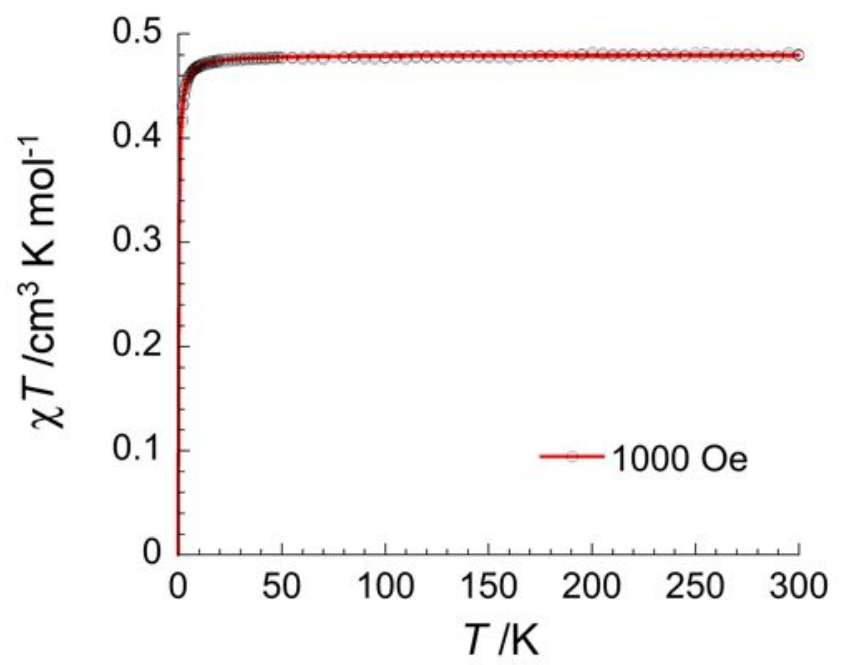

Figure S13. Temperature dependence of the dc magnetic susceptibility ( $\chi=M / H$ per mole of complex) plotted as $\chi^{T}$ vs $T$ for [Co"(Py $\left.\mathbf{I m A m}\right)_{2}$ ], collected under an applied field of 1000 Oe. The solid red line corresponds to the best fit to a Curie-Weiss law for an $S=1 / 2$ spin $(g=2.26(5), \theta=-0.26(2) \mathrm{K})$.

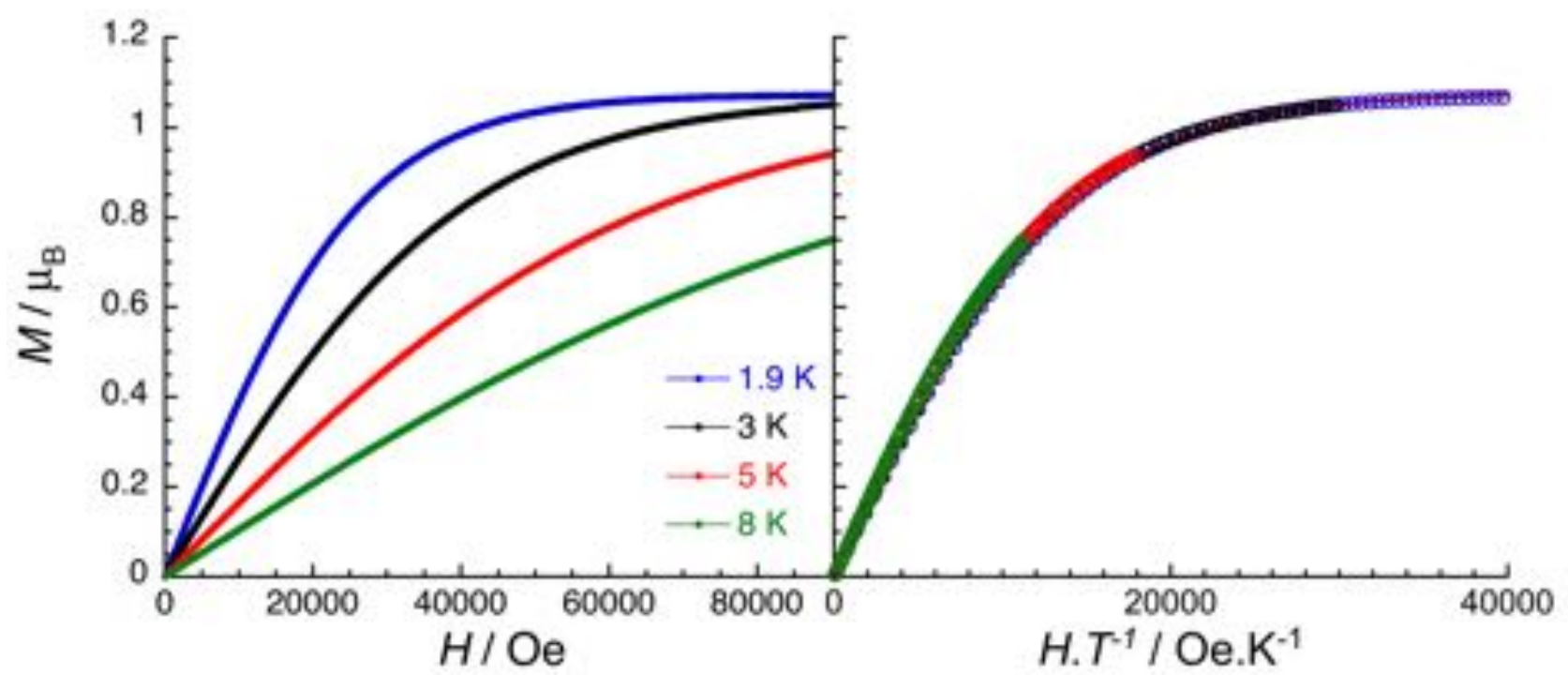

Figure S14. Field $(H)$ dependence of the magnetization $(M)$ plotted as $M$ vs $H$ (left) and $M$ vs $H / T$ (right) for [Co"(Py $\left.1 \mathrm{mAm})_{2}\right]$ at the indicated temperatures $(T)$. The solid line on the $M$ vs $H / T$ data is the best fit to the $S=1 / 2$ Brillouin function with $g=2.16(5)$. 


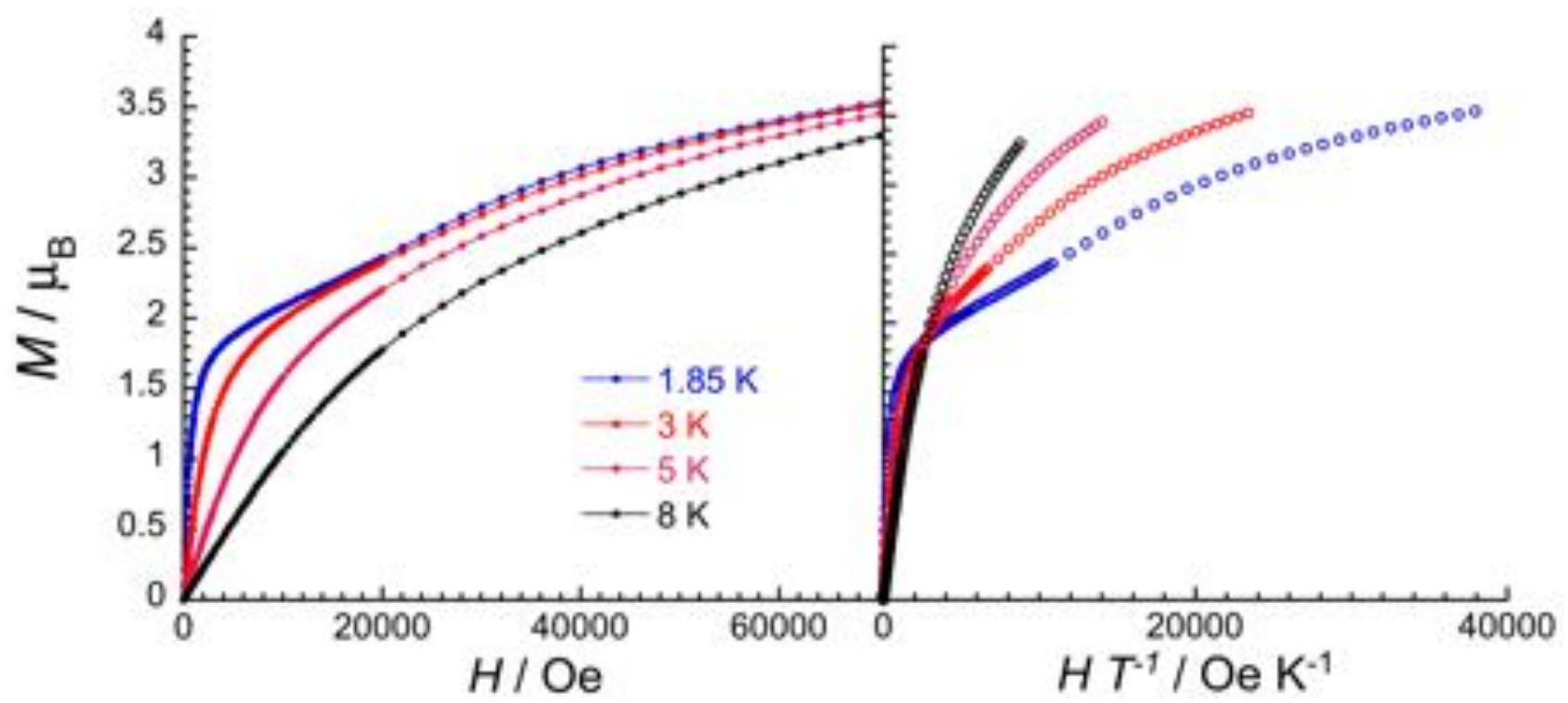

Figure S15. Field $(H)$ dependence of the magnetization ( $M$ normalized per $\left[\mathrm{Co}_{3}{ }_{3}\left(\mathrm{Pm}_{2} \mathrm{ImAm}\right)_{2} \mathrm{Cl}_{4}\right]$ unit) plotted as $M$ vs $H$ (left) and $M$ vs $H / T$ (right) for $\left[\mathrm{Co}_{3}\left(\mathbf{P m}_{2} \mid \mathbf{m A m}\right)_{2} \mathrm{Cl}_{4}\right] \cdot 5 \mathrm{H}_{2} \mathbf{O}$ at the indicated temperatures $(T)$.

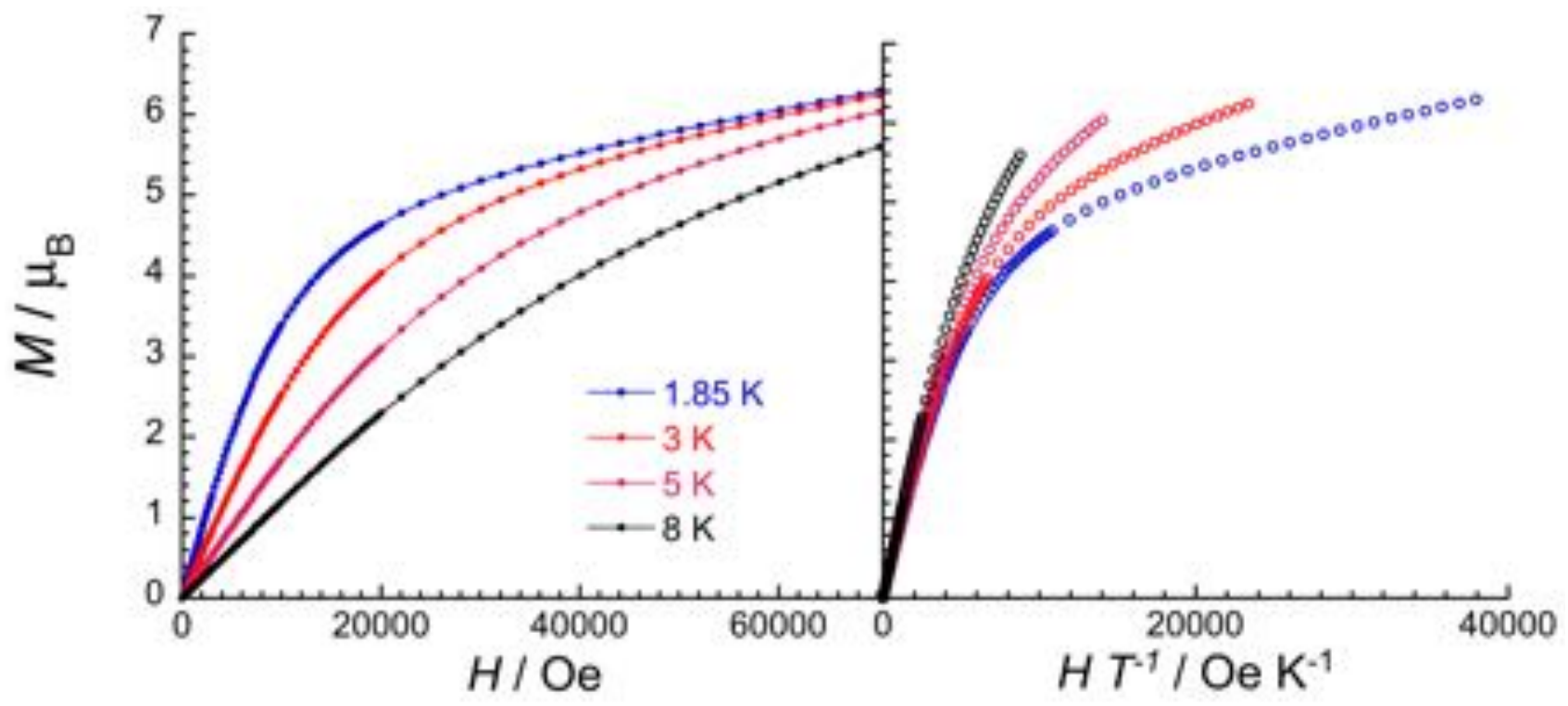

Figure S16. Field $(H)$ dependence of the magnetization $\left(M\right.$, normalized per $\left[\mathrm{Co}_{6}{ }_{6}(\mu-\mathrm{Cl})_{2}\left(\mathrm{Pm}_{2} \mathrm{ImAm}\right)_{4} \mathrm{Cl}_{6}\right]$ unit) plotted as $M$ vs $H$ (left) and $M$ vs $H / T$ (right) for $\left[\mathrm{Co}_{6}{ }_{6}\left(\mu-\mathrm{Cl}_{2}\left(\mathrm{Pm}_{2} \mathrm{ImAm}\right)_{4} \mathrm{Cl}_{8}\right] \cdot 2 \mathrm{CH}_{3} \mathrm{OH} \cdot \mathbf{2}^{\mathrm{CH}_{2}} \mathrm{Cl}_{2}\right.$ at the indicated temperatures $(T)$. 

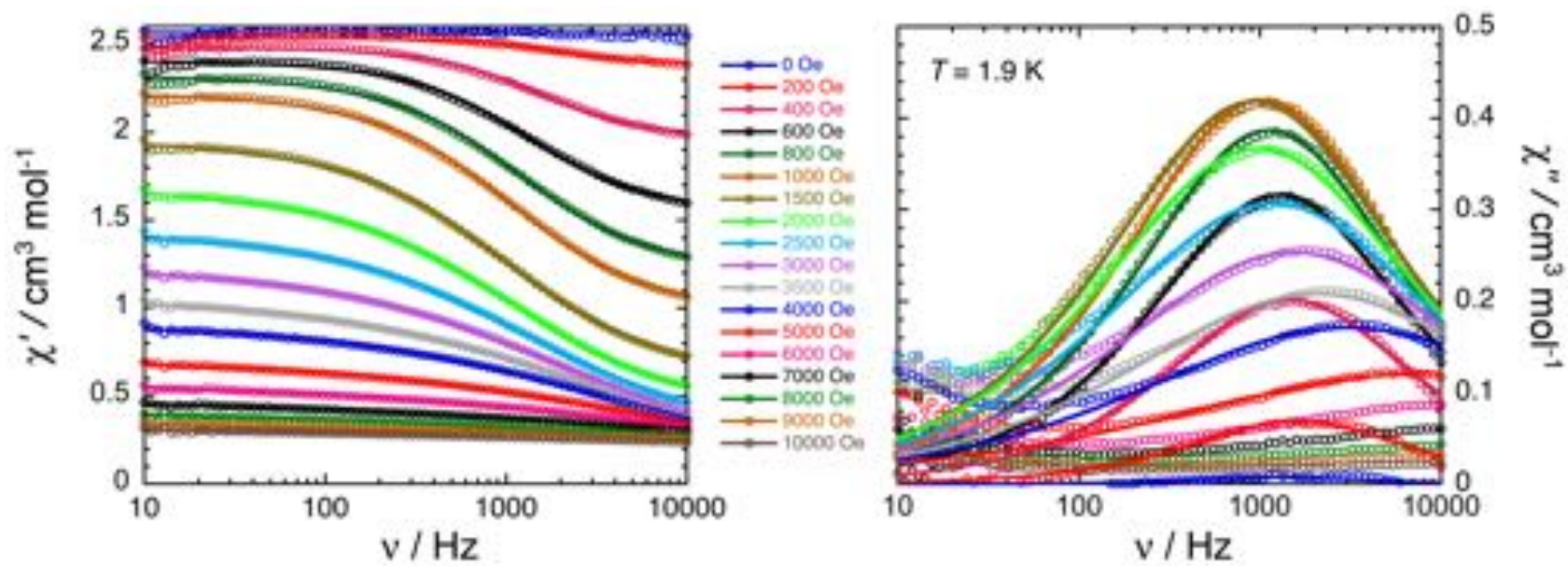

Figure S17. Frequency dependence of the real $\left(\chi^{\prime}\right.$, left $)$ and imaginary ( $\chi^{\prime \prime}$, right) parts of the ac susceptibility (normalized per $\left[\mathrm{Co}_{6}(\mu-\mathrm{Cl})_{2}\left(\mathrm{Pm}_{2} \mathrm{ImAm}\right)_{4} \mathrm{Cl}_{6}\right]$ unit) for [Co" 6 ( $\boldsymbol{\mu}$ $\left.\mathrm{Cl}_{2}\left(\mathrm{Pm}_{2} \mathrm{ImAm}\right)_{4} \mathrm{Cl}_{8}\right] \cdot 2 \mathrm{CH}_{3} \mathrm{OH} \cdot 2 \mathrm{CH}_{2} \mathrm{Cl}_{2}$ collected at $1.9 \mathrm{~K}$ and varying dc fields. Solid lines are the best fits obtained with the Debye generalized model.
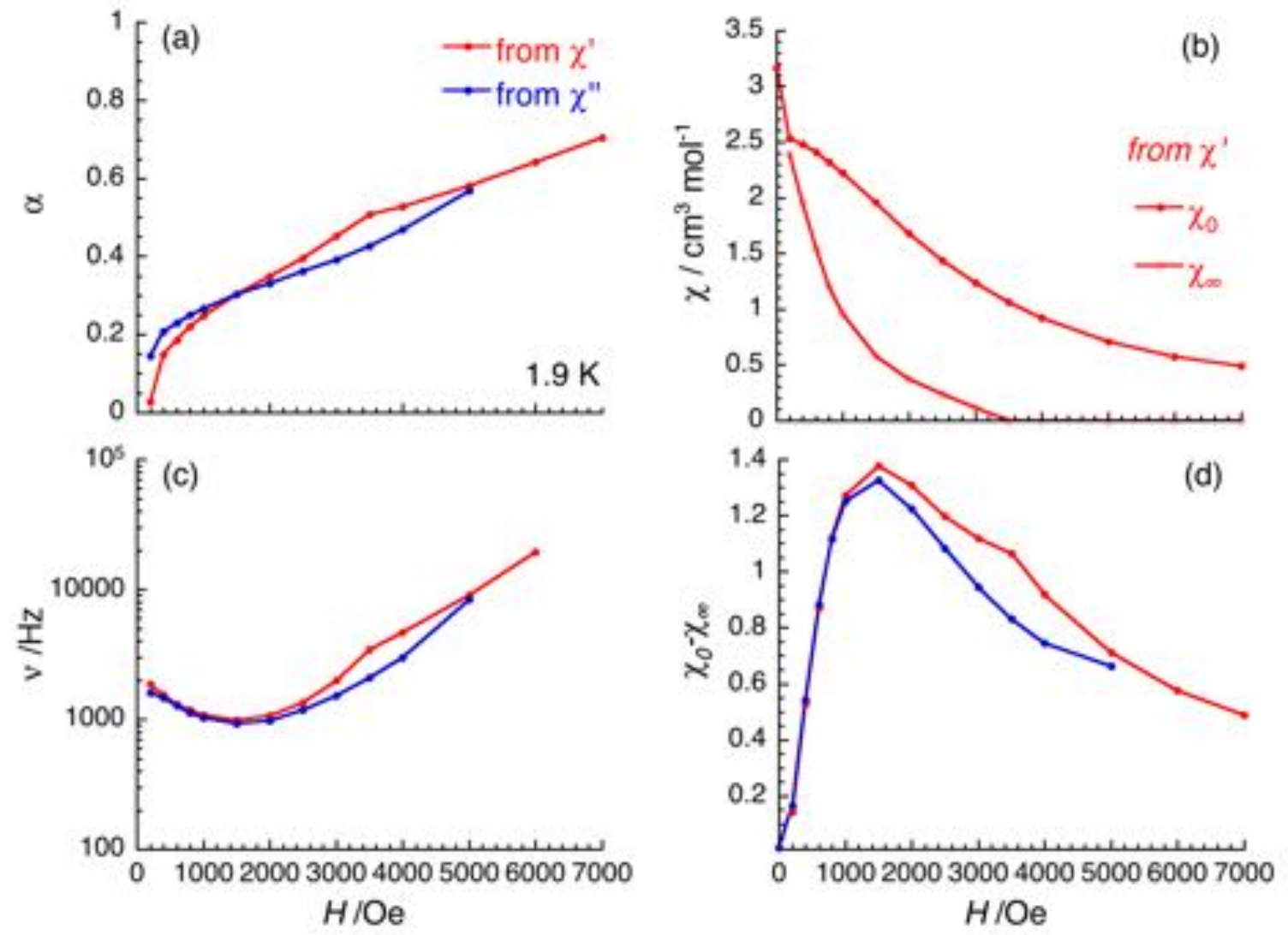

Figure S18. Field dependence of the parameters, $\alpha, v, \chi_{0}, \chi_{\infty}$ and $\chi_{0}-\chi_{\infty}$, between 0 and $0.7 \mathrm{~T}$ deduced from the generalized Debye fit of the frequency dependence of the real $\left(\chi^{\prime}\right)$ and imaginary $\left(\chi^{\prime \prime}\right)$ components of the ac susceptibility at $1.9 \mathrm{~K}$, shown in Figure S16, for [Co" $6{ }_{6}(\boldsymbol{\mu}$ $\left.\mathrm{Cl})_{2}\left(\mathrm{Pm}_{2} \mathrm{ImAm}\right)_{4} \mathrm{Cl}_{8}\right] \cdot 2 \mathrm{CH}_{3} \mathrm{OH} \cdot 2 \mathrm{CH}_{2} \mathrm{Cl}_{2}$. 

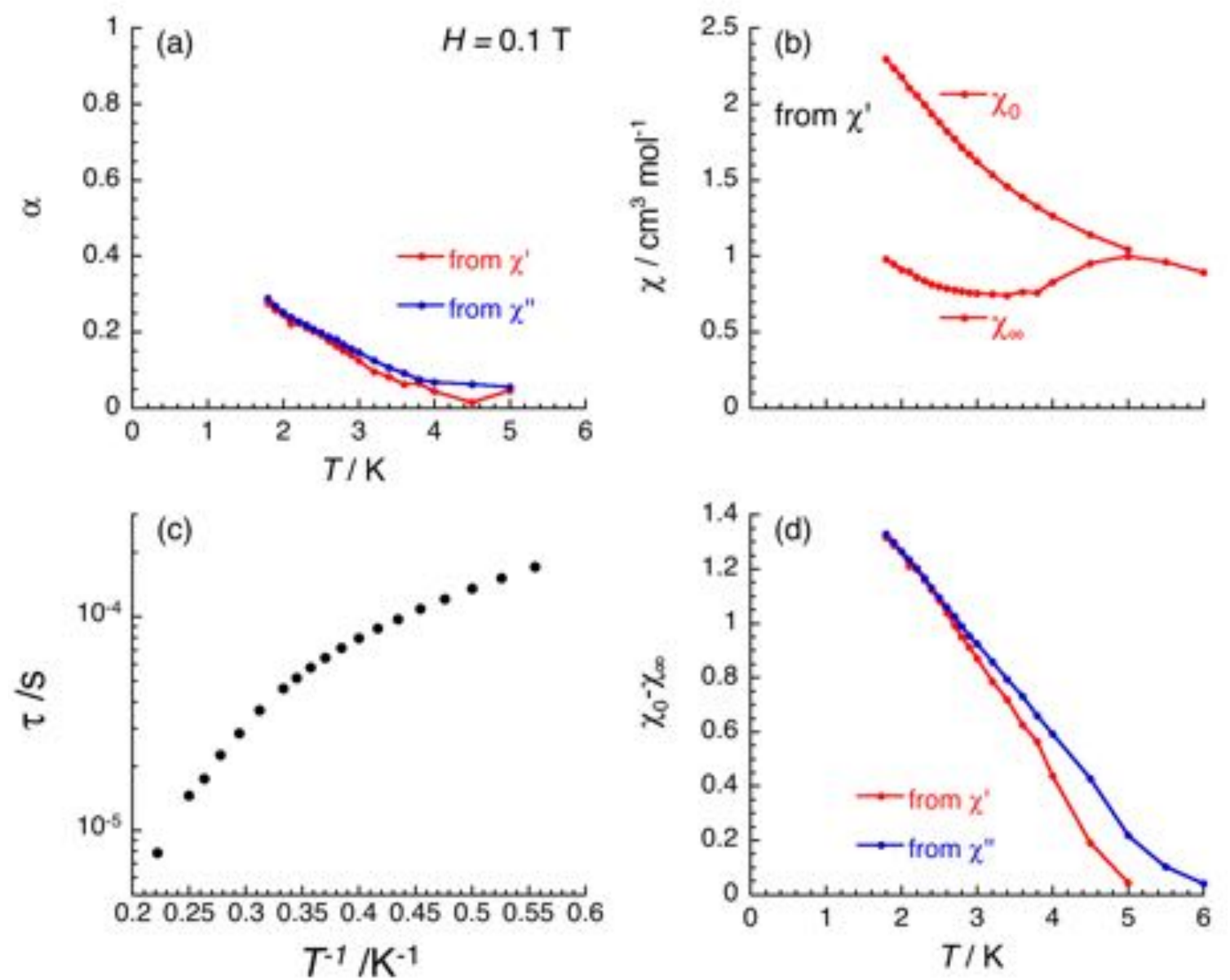

Figure S19. Temperature dependence of the parameters, $\alpha(\mathrm{a}), \chi_{0} \& \chi_{\infty}$ (b), $\tau$ (c) and $\chi_{0}-\chi_{\infty}$ (d) between 1.8 and $6 \mathrm{~K}$ deduced from the generalized Debye fit of the frequency dependence of the real $\left(\chi^{\prime}\right)$ and imaginary $\left(\chi^{\prime \prime}\right)$ components of the ac susceptibility at $0.1 \mathrm{~T}$, shown in Figure 3 of the main text for [ $\mathrm{Co}_{6}{ }_{6}(\boldsymbol{\mu}$ $\left.\mathrm{Cl}_{2}\left(\mathrm{Pm}_{2} \mathrm{ImAm}\right)_{4} \mathrm{Cl}_{8}\right] \cdot 2 \mathrm{CH}_{3} \mathrm{OH} \cdot \mathbf{2 C H}_{2} \mathrm{Cl}_{2}$. On the bottom left figure, the temperature dependence of the relaxation time of $\left[\mathrm{Co}_{6}{ }_{6}\left(\mu-\mathrm{Cl}_{2}\right)_{2}\left(\mathrm{Pm}_{2} \mathrm{ImAm}\right)_{4} \mathrm{Cl}_{8}\right] \cdot \mathbf{2 C H}_{3} \mathrm{OH} \cdot \mathbf{2 C H}_{2} \mathrm{Cl}_{2}$ is shown at $0.1 \mathrm{~T}$ between 1.8 and $4.5 \mathrm{~K}$ (treatment of $\chi^{\prime}$ versus $v$ and $\chi^{\prime \prime}$ versus $v$ curves gives undistinguishable results; both sets of data were averaged and plotted). 


\section{References}

1. R. Castañeda, A. Hollingshead, B. Gabidullin and J. L. Brusso, Cryst. Growth Des., 2017, 17, 65726578.

2. M. Yousaf, N. J. Yutronkie, R. Castañeda, J. A. Klein and J. Brusso, New J. Chem., 2017, 41, 1221812224.

3. C. F. Macrae, I. J. Bruno, J. A. Chisholm, P. R. Edgington, P. McCabe, E. Pidcock, L. RodriguezMonge, R. Taylor, J. van de Streek and P. A. Wood, J. Appl. Crystallogr., 2008, 41, 466-470.

4. $\quad$ Bruker, Bruker Analytical X-ray Instruments Inc., Madison, WI, 2016.

5. G. Sheldrick, Acta Crystallogr. A, 2015, 71, 3-8.

6. G. Sheldrick, Acta Crystallogr. C, 2015, 71, 3-8.

7. A. Spek, Acta Crystallogr. C, 2015, 71, 9-18. 